Sādhanā Vol. 38, Part 3, June 2013, pp. 331-358. (c) Indian Academy of Sciences

\title{
Space vector-based analysis of overmodulation in triangle-comparison based PWM for voltage source inverter
}

\author{
MANOJ KUMAR MODI ${ }^{1, *}$, S VENUGOPAL $^{2}$ \\ and G NARAYANAN ${ }^{1}$ \\ ${ }^{1}$ Department of Electrical Engineering, Indian Institute of Science, \\ Bangalore 560 012, India \\ ${ }^{2}$ Electrotherm India Limited, Coimbatore 641 014, India \\ e-mail: manojkumarmodi@gmail.com; venugopals@gmail.com; \\ gnar@ee.iisc.ernet.in
}

MS received 6 September 2010; revised 29 April 2013; accepted 3 May 2013

\begin{abstract}
The equivalence of triangle-comparison-based pulse width modulation (TCPWM) and space vector based PWM (SVPWM) during linear modulation is well-known. This paper analyses triangle-comparison based PWM techniques (TCPWM) such as sine-triangle PWM (SPWM) and common-mode voltage injection PWM during overmodulation from a space vector point of view. The average voltage vector produced by TCPWM during overmodulation is studied in the stationary (a-b) reference frame. This is compared and contrasted with the average voltage vector corresponding to the well-known standard two-zone algorithm for space vector modulated inverters. It is shown that the two-zone overmodulation algorithm itself can be derived from the variation of average voltage vector with TCPWM. The average voltage vector is further studied in a synchronously revolving $(\mathrm{d}-\mathrm{q})$ reference frame. The RMS value of low-order voltage ripple can be estimated, and can be used to compare harmonic distortion due to different PWM methods during overmodulation. The measured values of the total harmonic distortion (THD) in the line currents are presented at various fundamental frequencies. The relative values of measured current THD pertaining to different PWM methods tally with those of analytically evaluated RMS voltage ripple.
\end{abstract}

Keywords. Pulse width modulation; harmonic distortion; overmodulation; space vector; voltage ripple; voltage source inverter.

\section{Introduction}

Three-phase voltage source inverters (VSI) are widely employed for DC to AC conversion. The VSI is a three-phase bridge consisting of six active switches as shown in figure 1 . This is

*For correspondence 


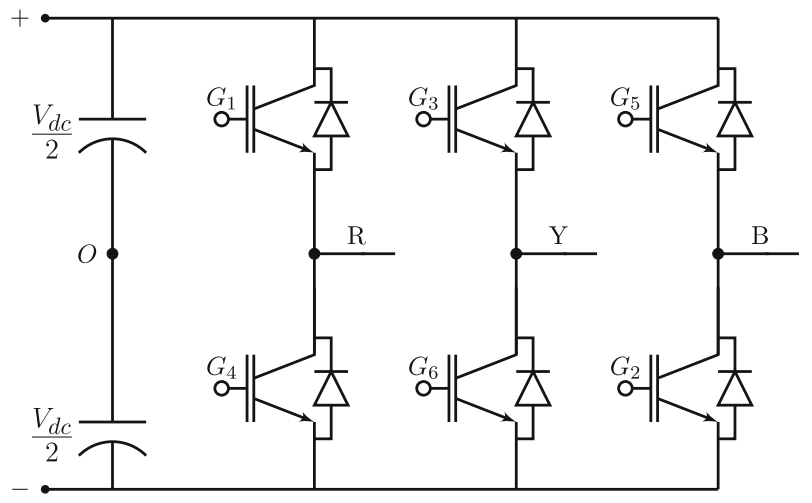

Figure 1. Schematic of a two-level voltage source inverter (VSI).

commonly used in power processing applications such as AC motor drives, static reactive power compensator (STATCOM) and active front end converter (FEC) (Mohan et al 2003).

In $\mathrm{AC}$ motor drives, the DC bus voltage $V_{d c}$ is usually fixed. The amplitude and frequency of the AC output voltage are controlled as required. Figure 2 a shows a VSI fed induction motor drive. The motor drive can be controlled either in an open-loop or closed-loop fashion. Constant volts per hertz $(V / f)$ control is a commonly used open-loop control method. Closed-loop control methods such as vector control or field oriented control are used for fast dynamic response (Ranganathan 2010; Bose 2009).

Diode bridge and thyristor converters are traditionally used for rectification. These draw non-sinusoidal currents from the mains at low power factors. A VSI can be used as an active PWM rectifier or a front-end converter (FEC), as illustrated in figure 2b. An FEC draws 'nearsinusoidal' currents from the mains at high power factors (Bose 2009; Prasad et al 2008; Zhang et al 2012). The input power factor can actually be adjusted, and the converter can be made to

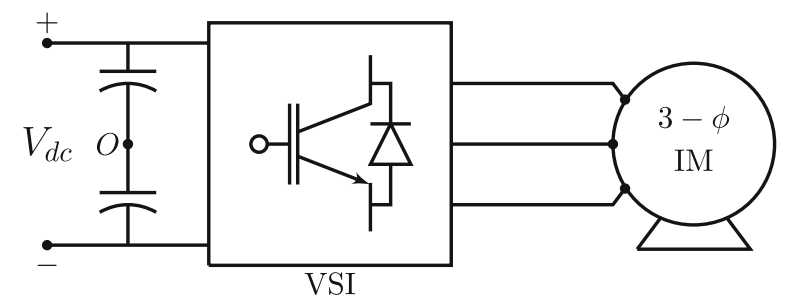

(a)

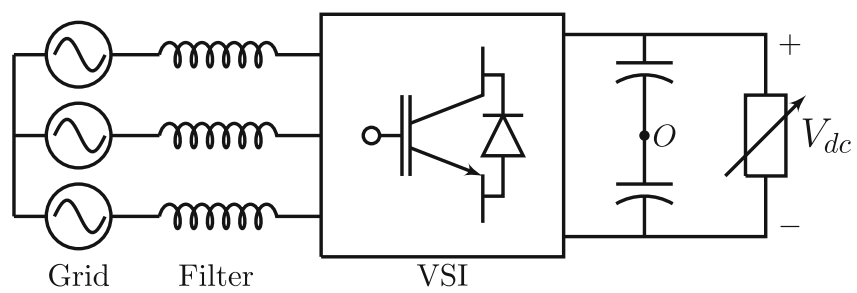

(b)

Figure 2. Applications of a VSI. (a) VSI fed induction motor drive. (b) Front end converter. 
supply reactive power to the grid or other loads connected in parallel (Singh et al 2009, 1998). An FEC or STATCOM requires appropriate closed-loop control (Prasad et al 2008; Zhang et al 2012; Singh et al 2009, 1998).

In a motor drive, both amplitude and frequency of the line-side voltage are controlled as mentioned earlier. In an FEC or a STATCOM, the AC-side voltage is modulated at the linefrequency, while the amplitude and phase are controlled as required.

In all the above cases, pulse width modulation (PWM) is employed to produce (near) sinusoidal AC voltage of appropriate frequency, phase and amplitude. The PWM waveforms for a VSI are usually generated either based on triangle-comparison or using the space vector approach (Narayanan \& Ranganathan 2000; Ranganathan 1997; Zhao 2006; Mao et al 2011; Holtz 1992, 1994; Asiminoaei et al 2008; Wu et al 2011; Vguyen et al 2011; Chung et al 1998; Cataliotti et al 2007; Zhou \& Wang 2002; Varma \& Narayanan 2006).

In triangle-comparison PWM (TCPWM), three-phase modulating signals are compared against a common, high-frequency, bipolar, triangular carrier to produce the three-phase PWM waveforms. Sine-triangle PWM (SPWM) employs three phase sinusoids (or co-sinusoids) as the modulating signals $\left(m_{R}, m_{Y}, m_{B}\right)$ as shown in (1)

$$
\begin{aligned}
& m_{R}=V_{m} \cos (\omega t) \\
& m_{Y}=V_{m} \cos \left(\omega t-\frac{2 \pi}{3}\right) \\
& m_{B}=V_{m} \cos \left(\omega t-\frac{4 \pi}{3}\right),
\end{aligned}
$$

where $V_{m}$ is the peak value of the modulating sinusoids and $\omega$ is the fundamental angular frequency. The sinusoidal modulating signal of R-phase is illustrated in figure $3 \mathrm{a}$.

Several variants of sine-triangle PWM have been researched (Holtz 1992, 1994; Asiminoaei et al 2008; Wu et al 2011; Vguyen et al 2011; Chung et al 1998; Cataliotti et al 2007). Certain common-mode component $m_{c m}$ is added to three-phase sinusoidal signals as indicated in (2).

$$
\begin{aligned}
& m_{R}^{*}=V_{m} \cos (\omega t)+m_{c m} \\
& m_{Y}^{*}=V_{m} \cos \left(\omega t-\frac{2 \pi}{3}\right)+m_{c m} \\
& m_{B}^{*}=V_{m} \cos \left(\omega t-\frac{4 \pi}{3}\right)+m_{c m} .
\end{aligned}
$$

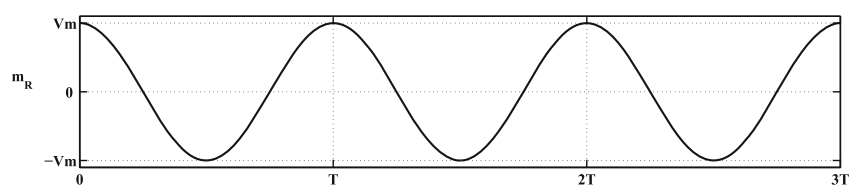

(a)

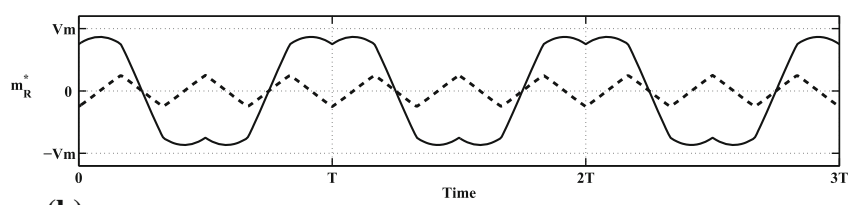

(b)

Figure 3. Modulating signals for (a) sine-triangle PWM and (b) common-mode voltage injection PWM. 
The common-mode component could simply be a third harmonic (i.e., $3 \omega$ ) component, or could consist of odd triplen frequencies such as $3 \omega, 9 \omega, 15 \omega$, etc. An example of the common-mode signal is shown in dashed lines in figure $3 \mathrm{~b}$. The modulating signal with the common-mode component added is indicated in solid lines in the same figure.

Figure 4 illustrates the determination of switching instants in a carrier cycle (i.e., $2 T_{S}$ ) with sine-triangle PWM. The three-phase PWM waveforms over the carrier cycle are shown at the bottom of the same figure. These waveforms can be viewed in terms of the inverter state applied or the corresponding voltage vector, which are defined in figure 5. The sequence of inverter state during the falling half-carrier cycle is,,,---+--++-+++ (i.e., 0-1-2-7) as shown in figure 4. Similarly, the inverter state sequence in the rising half-carrier cycle is (7-2-1-0) (Varma $\&$ Narayanan 2006). The average value of the applied voltage vector over a half-carrier cycle or subcycle $T_{s}$, namely $\mathbf{V}$, is given by

$$
\mathbf{V}=\mathbf{0} T_{0}+\mathbf{1} \angle 0^{\circ} T_{1}+\mathbf{1} \angle 60^{\circ} T_{2}+\mathbf{0} T_{7},
$$

where $T_{0}, T_{1}, T_{2}$ and $T_{7}$ are the respective durations for which the inverter state $0,1,2$ and 7 are applied in the subcycle. This average voltage vector falls in sector-I as shown in figure 5 for $m_{R}>m_{Y}>m_{B}$. The average voltage vectors produced over different sub-cycles in a line cycle

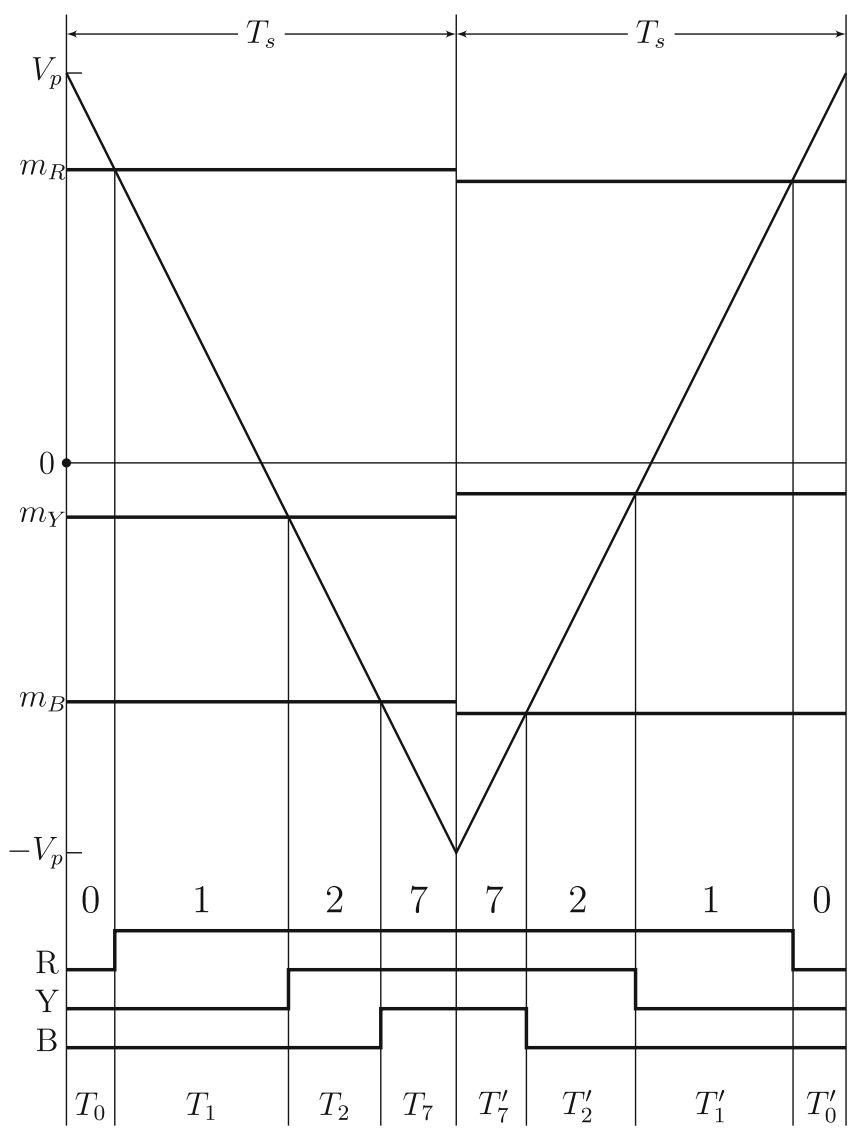

Figure 4. Equivalence of triangle-comparison and space vector PWM methods. 


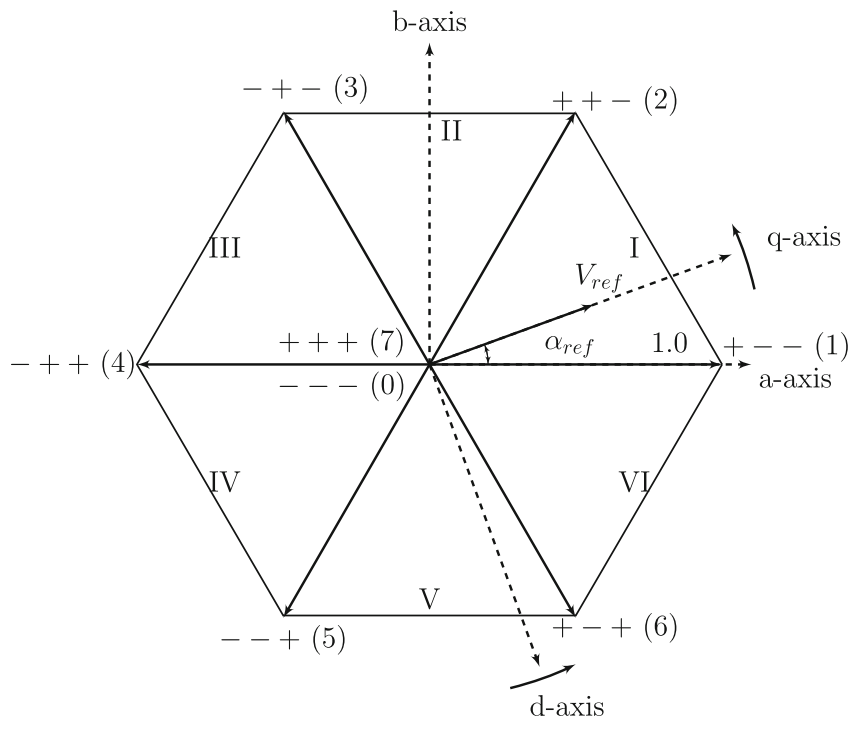

Figure 5. Switching states and voltage vectors produced by a two-level VSI. The voltage vectors are normalized with respect to DC bus voltage $V_{d c}$. I to VI are sectors.

are illustrated in figure 6 for $m=V_{m} / V_{p}=1$, where $V_{p}$ is the peak value of the triangular carrier. The average voltage vector $\mathbf{V}$ can be seen to have a constant magnitude. The angle between the average voltage vectors, produced during consecutive subcyles, is $\omega T_{s}$. One can see that the voltage vectors shown in figure 6 are samples of a vector revolving at a constant angular frequency of $\omega$, taken at uniform intervals of $T_{s}$. Thus, the average voltage vector applied has constant magnitude and constant angular frequency (equal to the fundamental angular frequency) during linear modulation (Varma \& Narayanan 2006).

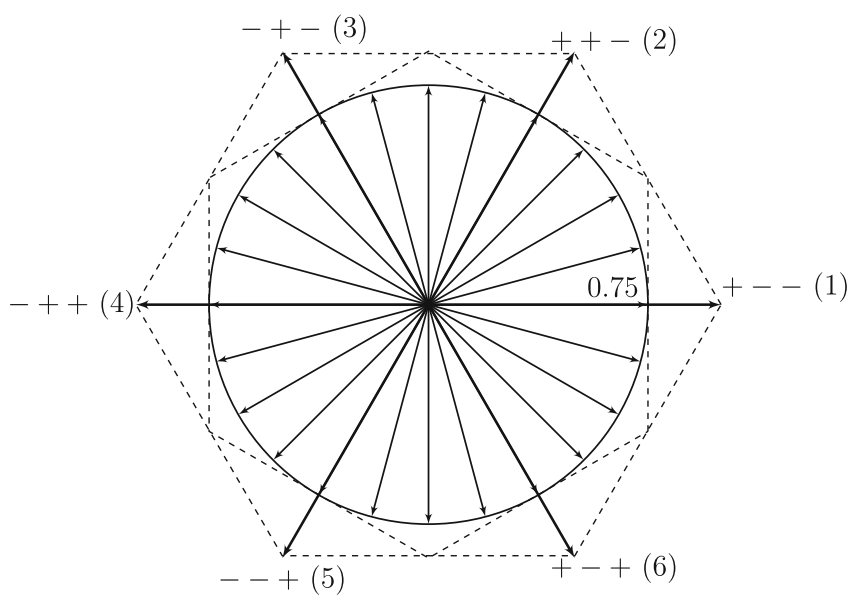

Figure 6. Averaged voltage vectors produced by a two-level VSI using sine-triangle PWM with $V_{m} / V_{p}=1$. 
In case of common-mode injection PWM, a common-mode signal is added to the three modulating signals $\left(m_{R}, m_{Y}, m_{B}\right)$. This causes the switching instants of all three phases to get shifted to the same extent in the given half-carrier cycle. Hence the dwell times of the two active states, namely $T_{1}$ and $T_{2}$, are unchanged. However, $T_{0}$ and $T_{7}$ are now different (though they still add up to the same $T_{z}$ ). The common mode signal, shown in figure $3 \mathrm{~b}$, results in $T_{0}$ and $T_{7}$ being equal to $0.5 T_{z}$ (Chung et al 1998; Cataliotti et al 2007; Zhou \& Wang 2002; Varma \& Narayanan 2006). The average voltage vector produced over the subcycle is the same as that with SPWM. Hence, for the common mode voltage injection PWM also, the average voltage vector applied has constant magnitude and angular velocity similar to figure 6 .

Thus, during linear modulation the average voltage vectors produced over different subcycles by TCPWM are similar to those produced by space vector based PWM. The equivalence of the two approaches in the linear modulation zone is well-established (Chung et al 1998; Cataliotti et al 2007; Zhou \& Wang 2002; Varma \& Narayanan 2006). This paper investigates the equivalence, if any, of the two approaches during overmodulation.

During overmodulation, the peak value of the modulating signal exceeds that of the carrier. Hence the three-phase average voltages are no longer sinusoidal. Therefore, the average voltage vector applied can no longer have constant magnitude as well as uniform angular velocity as in case of linear modulation. To the authors' knowledge, the nature of variations in the magnitude and angular velocity of the average voltage vector during overmodulation with TCPWM has not been studied and documented in the literature. Further, these variations would also depend on the modulating signal, as will be shown in later sections of this paper.

With TCPWM, the fundamental voltage can be increased (or decreased) by simply increasing (or decreasing) the peak value of modulating sinusoid, i.e., $V_{m}$ in equation (1) or (2) as the case may be. In other words, the fundamental voltage can be controlled by $V_{m}$ although the relationship between the two is nonlinear during overmodulation. However, space vector-based PWM methods require an overmodulation algorithm for voltage control during overmodulation (Beig 2012; Holtz et al 1993; Lee \& Lee 1998; Narayanan \& Ranganathan 2001, 2002; Venugopal \& Narayanan 2006; Bolognani \& Zigliotto 1997; Kerkman et al 2006). Numerous overmodulation algorithms have been proposed in the literature for space vector modulated inverter (Holtz et al 1993; Lee \& Lee 1998; Narayanan \& Ranganathan 2001, 2002; Venugopal \& Narayanan 2006; Bolognani \& Zigliotto 1997). The standard two-zone overmodulation algorithm (Holtz et al 1993; Lee \& Lee 1998) is the best known among them and also leads to less harmonic distortion in line current than the other algorithms (Narayanan \& Ranganathan 2002). Once again, to the authors' knowledge, the derivation of this algorithm has not been reported in the literature despite the popularity and widespread use of the algorithm. The analysis of TCPWM during overmodulation is used here to derive the equations pertaining to the standard two-zone algorithm.

Space vector-based PWM and the standard two-zone overmodulation algorithm are reviewed briefly in section 2. TCPWM is first studied from a space vector point of view in the stationary reference frame in section 3 . The above analysis is used to derive the equations pertaining to the standard two-zone algorithm in section 4. The analysis of TCPWM during overmodulation in the stationary reference is extended to a synchronously revolving (d-q) reference frame in section 5. Also, the RMS values of low-order voltage ripple, corresponding to different PWM methods, are evaluated and compared in this section. Experimental results and conclusion are presented in sections 6 and 7, respectively. Some preliminary results of this work have been presented in a conference publication (Modi et al 2010). Complete analysis and detailed results are presented here. 


\section{Overmodulation in space vector modulated inverter}

Space vector-based PWM and the standard two-zone overmodulation algorithm for space vector modulated inverters are explained in this section.

\subsection{Linear modulation}

Three-phase sinusoidal voltages get transformed into a revolving voltage vector in the space vector domain. In space vector-based PWM, a revolving voltage vector is used as the reference instead of three-phase modulating waves. The revolving reference voltage vector is sampled once in every subcycle $T_{s}$. The reference voltage vector in sector-I is realized by employing the two nearest active voltage vectors 1 and 2 along with the zero vector, which are shown in figure 5 . The active voltage vectors are applied for durations $T_{1}$ and $T_{2}$, respectively, in the given subcycle. The two zero states 0 and 7 together are applied for a duration $T_{z}$.

The dwell times $T_{1}, T_{2}$ and $T_{z}$ can be derived using volt-second balance. These can be calculated using the magnitude $V_{\text {ref }}$ and angle $\alpha_{\text {ref }}$ of the reference vector as shown in (4) (Narayanan \& Ranganathan 2000; Ranganathan 1997; Zhao 2006; Mao et al 2011; Holtz 1992, 1994; Varma \& Narayanan 2006; Holtz et al 1993; Lee \& Lee 1998; Narayanan \& Ranganathan 2001, 2002; Venugopal \& Narayanan 2006; Bolognani \& Zigliotto 1997).

$$
\begin{aligned}
& \frac{T_{1}}{T_{s}}=\left[V_{r e f}\right]\left[\frac{\sin \left(\frac{\pi}{3}-\alpha_{r e f}\right)}{\sin \frac{\pi}{3}}\right] \\
& \frac{T_{2}}{T_{s}}=\left[V_{r e f}\right]\left[\frac{\sin \alpha_{r e f}}{\sin \frac{\pi}{3}}\right] \\
& \frac{T_{z}}{T_{s}}=1-\frac{T_{1}}{T_{s}}-\frac{T_{2}}{T_{s}}
\end{aligned}
$$

The zero vector can be applied either using the zero state 0 or the zero state 7 . Different PWM techniques divide $T_{z}$ into $T_{0}$ and $T_{7}$ in different proportions (Chung et al 1998; Cataliotti et al 2007; Zhou \& Wang 2002; Varma \& Narayanan 2006). Conventional space vector PWM (CSVPWM) divides $T_{z}$ equally between the two zero states, i.e., $T_{0}=T_{7}=0.5 T_{z}$. The switching sequence starts from one zero state (say 0) and ends with other zero state (say 7), passing through the two active states. The sequence is the same as in case of SPWM as shown in figure 4.

The apportioning of $T_{z}$ between $T_{0}$ and $T_{7}$ in space vector-based PWM is equivalent to addition of common-mode signal in TCPWM (Chung et al 1998; Cataliotti et al 2007; Zhou \& Wang 2002; Varma \& Narayanan 2006). In fact, this equivalence is exploited to produce PWM waveforms corresponding to CSVPWM by comparing the modulating signal shown in figure $3 \mathrm{~b}$ with a triangular carrier. This significantly reduces the computational effort required (Chung et al 1998; Varma \& Narayanan 2006).

However, it should be noted that SVPWM has a wider choice of switching sequences than TCPWM. While CSVPWM employs the switching sequence (0-1-2-7), other sequences such as (0-1-2-1), (7-2-1-2), (1-0-1-2) and (2-7-2-1) can also be used for space vector-based PWM generation (Zhao et al 2010; Binoj Kumar et al 2013). These latter sequences involve switching a phase twice or applying an active vector twice within a subcycle, which is equivalent to a halfcarrier cycle. The PWM waveforms produced by such space vector-based techniques cannot be produced using TCPWM (Narayanan \& Ranganathan 2000). Thus, SVPWM is more general than TCPWM. However, this work is confined to sequence (0-1-2-7) only. 


\subsection{Overmodulation zone-I}

Linear modulation extends up to $V_{\text {ref }}=0.866$. The corresponding modulation index (MI) equals 0.907 . The modulation index (MI) is defined here as the ratio of the fundamental voltage applied to the fundamental voltage corresponding to six-step operation for a given DC bus voltage, i.e.,

$$
M I=\left[\frac{V_{1}}{\left(2 V_{d c} / \pi\right)}\right],
$$

where $V_{1}$ is the peak phase fundamental voltage applied to the load; $\left(2 V_{d c} / \pi\right)$ is the peak phase fundamental voltage during six-step operation; $V_{d c}$ is the dc bus voltage. At $M I=0.907$, the tip of the average voltage vector has a circular trajectory of radius $V_{c i r}=0.866$.

Beyond $M I=0.907$, the locus of the tip of the average voltage vector applied is partly circular of radius $V_{c i r}$ and partly hexagonal as shown in figure $7 \mathrm{a}$ and as can be seen from equation (6). This zone is called 'overmodulation zone-I'. In this zone, the magnitude $V$ and position $\alpha$ of the average voltage vector in a sector are given by (6).

$$
\begin{gathered}
|V|=\left\{\begin{array}{lc}
V_{c i r}, & 0 \leq \alpha_{\text {ref }} \leq \alpha_{\text {cir }} \\
\frac{\sqrt{3} / 2}{\cos \left(\frac{\pi}{6}-\alpha_{r e f}\right)}, & \alpha_{c i r}<\alpha_{r e f} \leq\left(\frac{\pi}{3}-\alpha_{c i r}\right) \\
V_{c i r}, & \left(\frac{\pi}{3}-\alpha_{c i r}\right)<\alpha_{r e f} \leq\left(\frac{\pi}{3}\right)
\end{array}\right. \\
\alpha=\angle V=\alpha_{r e f} .
\end{gathered}
$$

The magnitude of the average voltage vector applied is constant $\left(V_{\text {cir }}\right)$ in the circular portion of the trajectory, while it varies in the hexagonal portion of the locus. The angle $\alpha$ of the average voltage vector is equal to the angle $\alpha_{\text {ref }}$ of the reference voltage vector [see equation (6)], which revolves with a uniform angular velocity. Thus, the average voltage vector applied has a nonuniform magnitude but revolves with a uniform angular velocity (Holtz et al 1993; Lee \& Lee 1998; Narayanan \& Ranganathan 2001, 2002).

The fundamental voltage is controlled by varying $V_{c i r}$ between 0.866 and 1.0, or $\alpha_{c i r}$ between $30^{\circ}$ and $0^{\circ}$. When $V_{\text {cir }}=1$ or $\alpha_{\text {cir }}=0^{\circ}$, the locus of the tip of the average voltage vector is fully hexagonal. This corresponds to $M I=0.952$ (Holtz et al 1993; Lee \& Lee 1998; Narayanan \& Ranganathan 2001, 2002).

\subsection{Overmodulation zone-II}

For fundamental voltages greater than 0.952 times the six-step fundamental voltage, the tip of the average voltage vector applied is always on the hexagon as shown in figure $7 \mathrm{~b}$. To increase MI beyond 0.952 , or to increase the fundamental voltage further, the average voltage vectors are moved closer to the nearest active vector (Narayanan \& Ranganathan 2001, 2002). The standard two-zone algorithm performs this using the notion of holding angle $\alpha_{h}$. The angle of the applied 
voltage vector $(\alpha)$ is related to $\alpha_{h}$ as illustrated in figure 8. The magnitude $V$ and position $\alpha$ of the average voltage vector in a sector are given by (7) (Holtz et al 1993; Lee \& Lee 1998).

$$
\alpha=\left\{\begin{array}{lc}
0, & 0 \leq \alpha_{r e f} \leq \alpha_{h} \\
\frac{\pi}{6}\left(\frac{\alpha_{r e f}-\alpha_{h}}{\frac{\pi}{6}-\alpha_{h}}\right), & \alpha_{h}<\alpha_{r e f} \leq\left(\frac{\pi}{3}-\alpha_{h}\right) \\
\left(\frac{\pi}{3}\right), & \left(\frac{\pi}{3}-\alpha_{h}\right)<\alpha_{r e f} \leq\left(\frac{\pi}{3}\right)
\end{array}\right.
$$

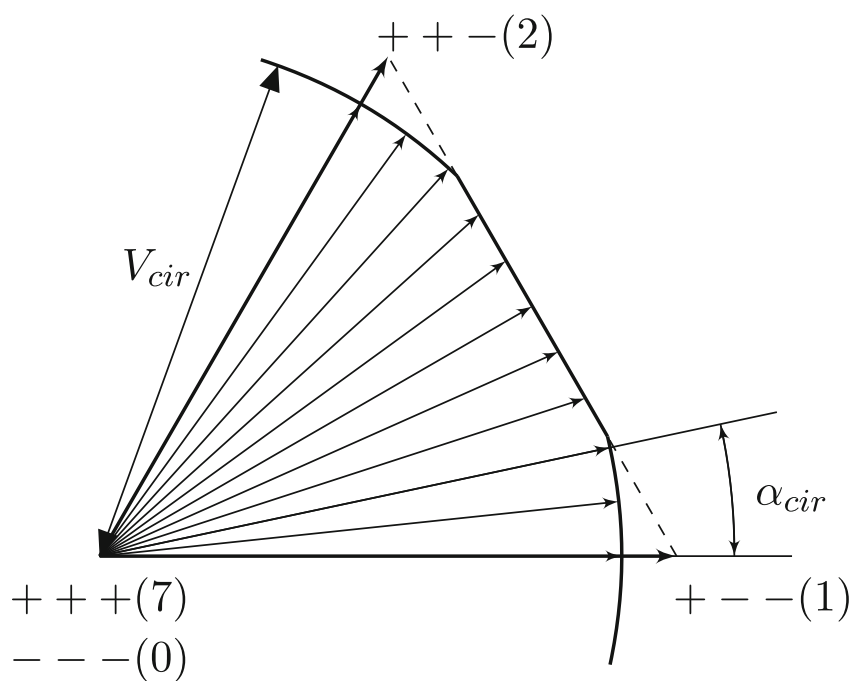

(a) Zone-I

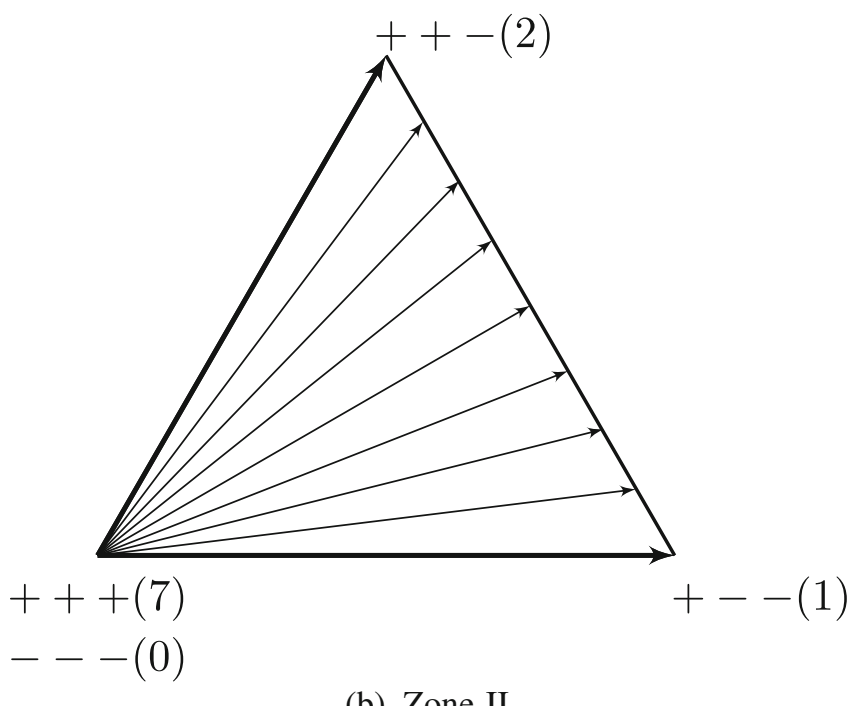

(b) Zone-II

Figure 7. Average voltage vectors produced by zone-I and zone-II. 


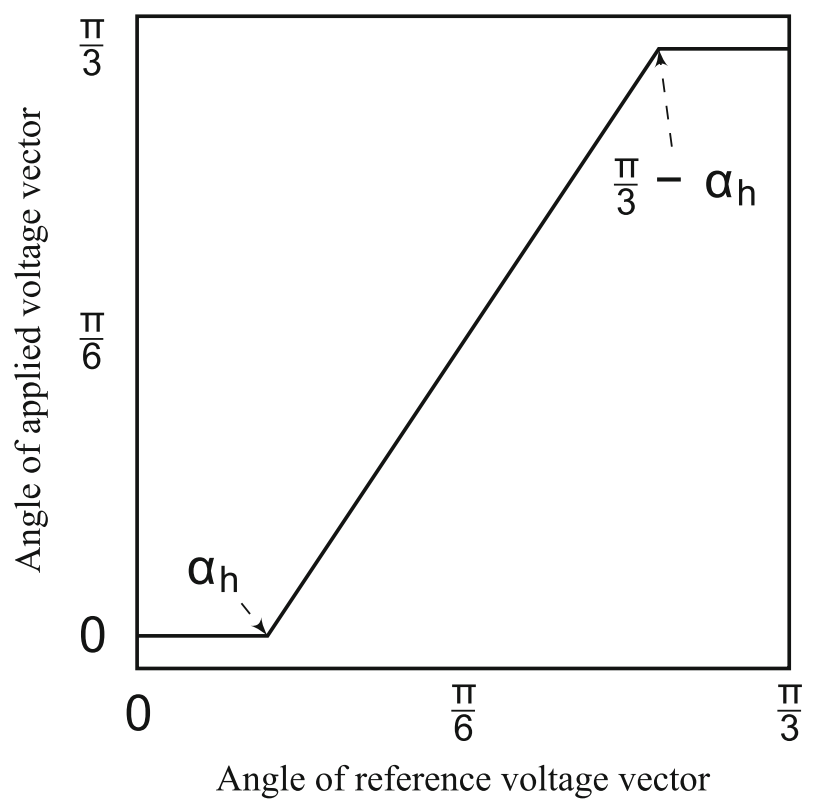

Figure 8. Angle of the reference voltage vector in zone-II.

$$
|V|=\frac{\sqrt{3} / 2}{\cos \left(\frac{\pi}{6}-\alpha\right)}
$$

As seen from figure 8, during the interval $0 \leq \alpha_{\text {ref }} \leq \alpha_{h}$ and $\left(\frac{\pi}{3}-\alpha_{h}\right) \leq \alpha_{\text {ref }} \leq\left(\frac{\pi}{3}\right)$, $\alpha$ remains constant against $\alpha_{\text {ref }}$ (or time); the angular velocity of the applied voltage vector is zero. The active vector 1 and active vector 2 are applied during these two intervals, respectively. However, in the intermediate interval $\alpha_{h} \leq \alpha_{\text {ref }} \leq\left(\frac{\pi}{3}-\alpha_{h}\right)$, the angle $\alpha$ rises with a uniform slope; the average voltage vector moves at a constant angular velocity higher than the fundamental angular frequency. Thus, the angular velocity of the average voltage vector applied is non-uniform. Since the trajectory of the tip of the applied vector is fully hexagonal (and not circular), the magnitude of applied vector is also non-uniform. At the end of zone-II, i.e., $\alpha_{h}=30^{\circ}$, $M I=1$ or six-step operation is achieved.

\section{Analysis of TCPWM during overmodulation in stationary reference frame}

The average voltage vector produced by sine-triangle PWM and that by common-mode voltage injection PWM are studied in the stationary reference frame. The carrier frequency is assumed to be much higher than the modulation frequency.

\subsection{Three-phase and two-phase average voltages}

The pole voltage (i.e., the voltage at the mid-point of an inverter leg, measured with respect to the mid-point of the DC bus) is either $+0.5 V_{d c}$ or $-0.5 V_{d c}$, depending on whether the top or bottom device is on. The pole voltages, averaged over a subcycle or half-carrier cycle, are termed 
as average pole voltages $\left(V_{r o}, V_{y o}, V_{b o}\right)$. The average pole voltage of R-phase $\left(V_{r o}\right)$ is given by (8). The average pole voltages $V_{y o}$ and $V_{b o}$ are defined similarly.

$$
V_{r o}=\left\{\begin{array}{lc}
0.5 V_{d c} \frac{m_{R}}{V_{p}}, & -V_{p} \leq m_{R} \leq V_{p} \\
0.5 V_{d c}, & m_{R}>V_{p} \\
-0.5 V_{d c}, & m_{R}<-V_{p} .
\end{array}\right.
$$

The three-phase line-line voltages $V_{r y}, V_{y b}$ and $V_{b r}$ are obtained from the average pole voltages $V_{r o}, V_{y o}$ and $V_{b o}$ as given by (9). The average line-neutral voltages $V_{r n}, V_{y n}$ and $V_{b n}$ are obtained as shown in (10).

$$
\begin{aligned}
V_{r y} & =\left(V_{r o}-V_{y o}\right) \\
V_{y b} & =\left(V_{y o}-V_{b o}\right) \\
V_{b r} & =\left(V_{b o}-V_{r o}\right) . \\
V_{r n} & =\frac{1}{3}\left(V_{r y}-V_{b r}\right) \\
V_{y n} & =\frac{1}{3}\left(V_{y b}-V_{r y}\right) \\
V_{b n} & =\frac{1}{3}\left(V_{b r}-V_{y b}\right) .
\end{aligned}
$$

The two-phase average voltages $V_{s a}$ and $V_{s b}$ are calculated as shown below in (11). These are the a-axis and b-axis components, respectively, of the average voltage vector in the stationary (a-b) reference frame (see figure 5).

$$
\begin{aligned}
& V_{s a}=\frac{3}{2} V_{r n}=\frac{1}{2}\left(2 V_{r o}-V_{y o}-V_{b o}\right) \\
& V_{s b}=\frac{\sqrt{3}}{2}\left(V_{y n}-V_{b n}\right)=\frac{\sqrt{3}}{2}\left(V_{y o}-V_{b o}\right) .
\end{aligned}
$$

The magnitude $|V|$ and position $\alpha$ of the average voltage vector are given by (12)

$$
|V|=\sqrt{V_{s a}^{2}+V_{s b}^{2}}, ; \angle V=\alpha=\arctan \left(\frac{V_{s b}}{V_{s a}}\right) .
$$

The average pole voltage $V_{r o}$, the average line voltage $V_{r y}$ and the average line-neutral voltage $V_{r n}$ corresponding to $m=V_{m} / V_{p}=1.35$ with sine-triangle PWM are illustrated in figure 9 . For this value of $m$, the modulating signal of a phase is beyond the carrier peak for roughly $84^{\circ}$ in every half cycle. Hence a phase is clamped for this duration in every half cycle as seen from $V_{\text {ro }}$ in figure 9. Approximately for $24^{\circ}$ (i.e., $84^{\circ}-60^{\circ}$ ), both R-phase and Y-phase are clamped in a half cycle. This is seen from $V_{r y}$ being equal to $+V_{d c}$ or $-V_{d c}$ over this duration. The waveform of $V_{r n}$ is also shown. One can see that $V_{r o}$ contains all odd harmonics (i.e., $3^{r d}, 5^{t h}, 7^{t h}, 9^{t h}$, etc.) in addition to the fundamental component. The triplen frequency components (i.e., $3^{r d}, 9^{t h}$, $15^{t h}$, etc.) are absent in $V_{r y}$ and $V_{r n}$. The harmonic spectrum of $V_{r n}$ is similar to that of $V_{r o}$ except for the absence of odd triplen harmonics. The average phase voltage $V_{r n}$ contains nontriplen odd harmonics (i.e., $5^{t h}, 7^{t h}, 11^{t h}, 13^{t h}$, etc.) in addition to the fundamental component. 


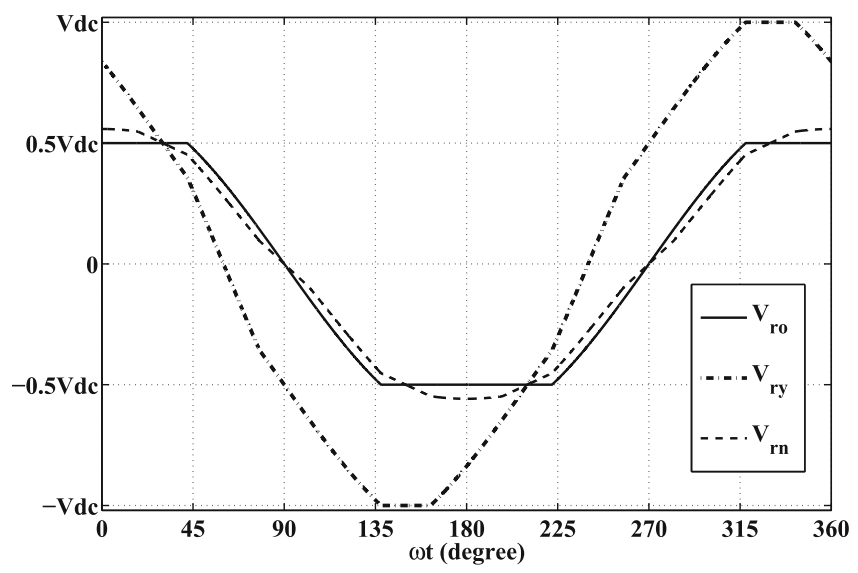

Figure 9. Average pole voltage $V_{r o}$, average line voltage $V_{r y}$, and average line to neutral voltage $V_{r n}$ for $V_{m} / V_{p}=1.35$.

Hence these harmonic components are also present in $V_{s a}$ and $V_{s b}$. These harmonics cause the magnitude $|V|$ to change with time, or the position $\alpha$ to change non-linearly with time, or both. This is investigated for SPWM and common-mode injection PWM in the following sub-sections.

\subsection{Sine-triangle $P W M$}

The overmodulation region is divided into different ranges of $m$ and the analysis is carried out in each range of $m$ as discussed below.

3.2a Ranges of $m$ : Three-phase average pole voltages $V_{r o}, V_{y o}$ and $V_{b o}$ are shown plotted for $m=1.075, m=1.35$ and $m=3$ in figures $10 \mathrm{a}, \mathrm{b}$ and $\mathrm{c}$, respectively. Due to pulse dropping, each phase gets clamped for certain duration $\theta_{\text {clamp }}$ in each half cycle of its fundamental voltage. This duration increases with $m$ as seen from figure 10 .

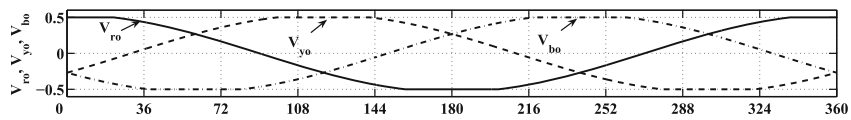

(a)

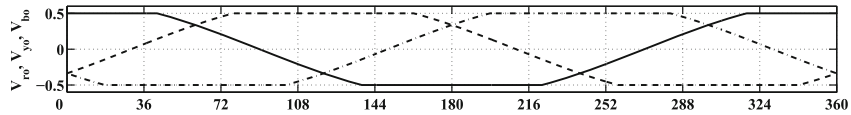

(b)

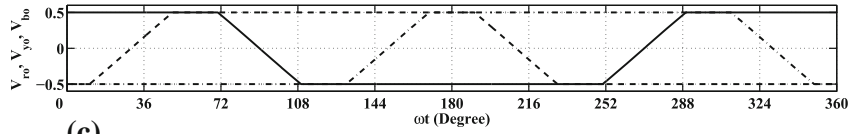

(c)

Figure 10. Three-phase average pole voltages $V_{r o}, V_{y o}, V_{b o}$, normalized with respect to $V_{d c}$, at $(\mathbf{a}) \mathrm{m}=$ 1.075 , (b) $\mathrm{m}=1.35$ and (c) $\mathrm{m}=3$ with SPWM. 


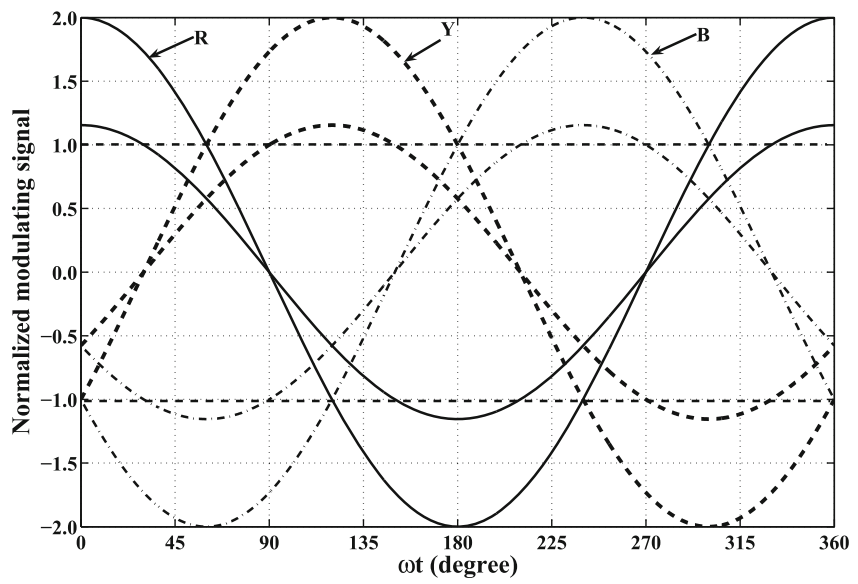

Figure 11. Three phase normalized sinusoidal modulating signals with $V_{m} / V_{p}=1.1547$ and 2 .

In figure 10a it can be observed that no phase or one phase is clamped in any carrier cycle. This is representative of the range $0^{\circ}<\theta_{\text {clamp }}<60^{\circ}$. When $\theta_{\text {clamp }}=60^{\circ}$, one of the phases is clamped in any given carrier cycle. This corresponds to $m=2 / \sqrt{3}$. The normalized modulating signal corresponding to $m=2 / \sqrt{3}$ is shown in figure 11 .

Figure $10 \mathrm{~b}$ shows that one phase is clamped in certain carrier cycles, while two phases are clamped in the other carrier cycles. This happens in the range $60^{\circ}<\theta_{\text {clamp }}<120^{\circ}$. When $\theta_{\text {clamp }}=120^{\circ}$, two of the phases are clamped in all carrier cycles. This corresponds to $m=2$. The corresponding normalized modulating signal is also shown in figure 11 .

Similarly, figure 10c illustrates that two or three phases are clamped in any given carrier cycle when $120^{\circ}<\theta_{\text {clamp }}<180^{\circ}$. $\theta_{\text {clamp }}=180^{\circ}$ corresponds to six-step operation.

Thus, the figures $10 \mathrm{a}-\mathrm{c}$ represent three different ranges of $\theta_{\text {clamp }}$, namely $0^{\circ}<\theta_{\text {clamp }}<60^{\circ}$, $60^{\circ}<\theta_{\text {clamp }}<120^{\circ}$ and $120^{\circ}<\theta_{\text {clamp }}<180^{\circ}$, respectively. The corresponding ranges of $m$ are $1<m \leq 2 / \sqrt{3}, 2 / \sqrt{3}<m \leq 2$ and $m>2$. Hence the overmodulation range with SPWM gets divided into three sub-ranges as shown in table 1 .

Thus, depending on the value of $m$, the whole operating region of sine-triangle PWM $(0 \leq$ $m \leq \infty)$ can be divided into one linear and three non-linear ranges. The average voltage vector is studied in all the four ranges. Figures 12 to 14 illustrate the variations in the average voltage vector over a cycle (or a sector) in the four ranges.

3.2b Linear range $(m \leq 1)$ : In the linear range, the two-phase average voltages $V_{s a}$ and $V_{s b}$ are sinusoidal as shown in figure 12a. The magnitude and angle of the average voltage vector have a period equal to one sixth of the fundamental cycle. These are plotted over a sector, i.e.,

Table 1. Ranges of $\theta_{\text {clamp }}, \mathrm{m}$ and MI for SPWM.

\begin{tabular}{lcc}
\hline Range of $\theta_{\text {clamp }}$ & Range of $\mathrm{m}$ & Range of MI \\
\hline- & $(0,1)$ & $(0,0.785)$ \\
$\left(0^{\circ}, 60^{\circ}\right)$ & $(1,2 / \sqrt{3})$ & $(0.785,0.855)$ \\
$\left(60^{\circ}, 120^{\circ}\right)$ & $(2 / \sqrt{3}, 2)$ & $(0.855,0.952)$ \\
$\left(120^{\circ}, 180^{\circ}\right)$ & $(2, \infty)$ & $(0.952,1)$ \\
\hline
\end{tabular}




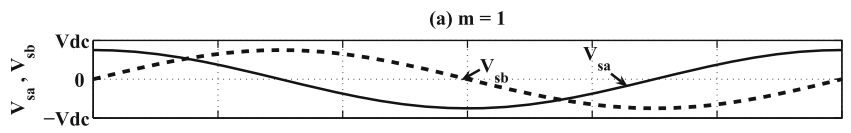

(b) $\mathrm{m}=1.075$

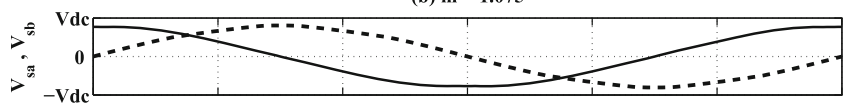

(c) $\mathrm{m}=1.35$
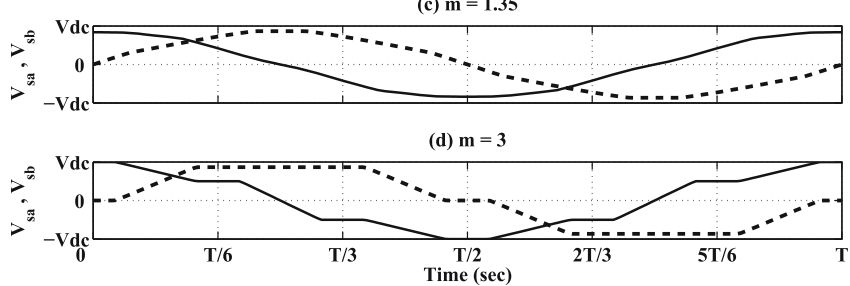

Figure 12. Two-phase average voltages $\left(V_{s a}, V_{s b}\right)$ for $m=1,1.075,1.35$ and 3 .

$\alpha_{\text {ref }}$ varying from $0^{\circ}$ to $60^{\circ}$, in figure $13 \mathrm{a}$. The magnitude is constant as seen from the figure. The angle varies linearly with time or fundamental angle; the angular velocity is constant. The average voltage vector applied in different subcycles over a sector is shown in figure 14a.

3.2c Non-linear range- $A\left(1<m \leq \frac{2}{\sqrt{3}}\right)$ : For any $m>1$, the ac side voltage is not proportional to $m$ with SPWM. In the non-linear range-A, the average pole voltages, and hence $V_{s a}$ and $V_{s b}$, are no longer sinusoidal as shown in figure $12 \mathrm{~b}$. The angular frequency is still constant. However, the magnitude of the average voltage vector is no longer constant as brought out by figure $13 \mathrm{~b}$ and figure $14 \mathrm{~b}$.

$3.2 \mathrm{~d}$ Non-linear range- $B\left(\frac{2}{\sqrt{3}}<m \leq 2\right)$ : In this range, the magnitude of the voltage vector is non-uniform. The angular frequency varies around the fundamental frequency, but the variation is negligible. Results of the analysis for $m=1.35$ in this range are shown in figure 12c, figure 13c and figure $14 \mathrm{c}$.

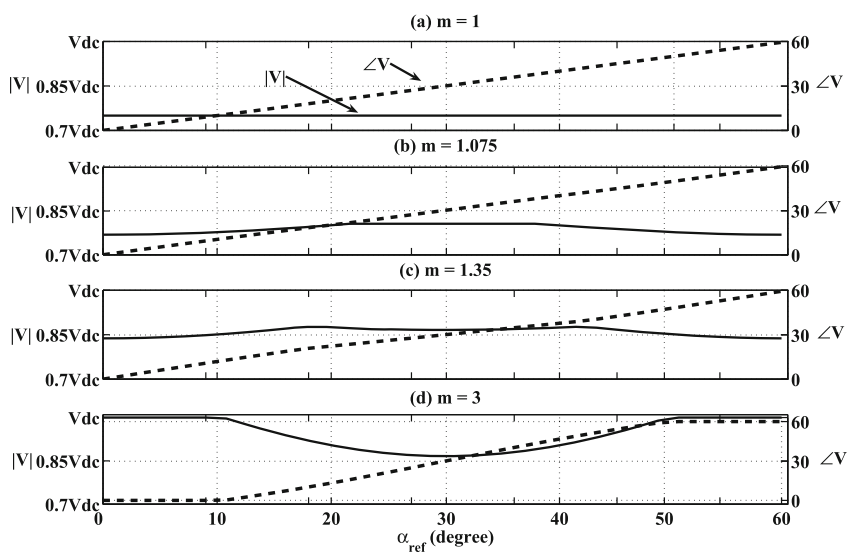

Figure 13. Magnitude $(|V|)$ and position of the average voltage vector for $m=1,1.075,1.35$ and 3 . 


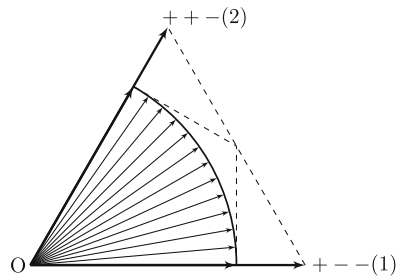

(a) $m=1$

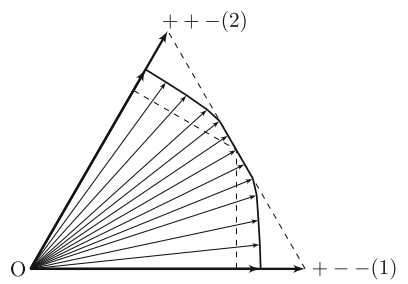

(c) $m=1.35$

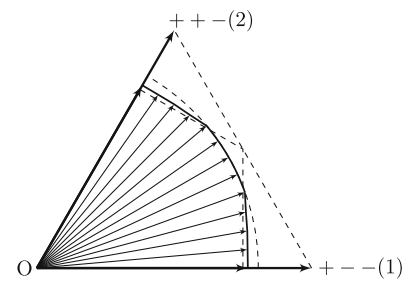

(b) $m=1.075$

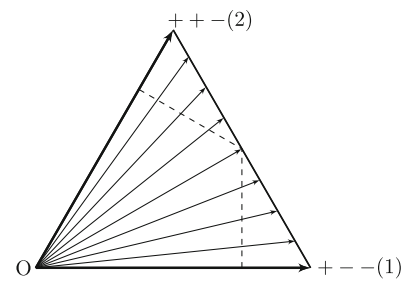

(d) $m=3$

Figure 14. Average voltage vectors produced by sine-triangle PWM for $m=1,1.075,1.35$ and 3 .

3.2e Non-linear range-C $(2<m<\infty)$ : In this range, when all three phases are clamped, an active vector is applied continually. As $m$ increases, the duration for which the active vector is continually applied increases. Finally, during six-step or square-wave operation, every active vector is applied for one sixth of the fundamental cycle. In this range both magnitude and angular velocity of the average voltage vector are non-uniform. The results corresponding to $m=3$ are presented in figures $12 \mathrm{~d}, 13 \mathrm{~d}$ and figure $14 \mathrm{~d}$.

\subsection{Common-mode voltage injection PWM}

The modulating signal, employed for the common-mode voltage injection PWM, is illustrated in figure $3 b$. During linear modulation, i.e., $m \leq 2 / \sqrt{3}$, this PWM method is equivalent to or produces the same PWM waveforms as CSVPWM as explained in section 1 and section 2.1 (Varma $\&$ Narayanan 2006). At the end of linear modulation, i.e., when $m=2 / \sqrt{3}$, the peak value of the modulating signal just equals the carrier peak as seen from figure 15 . During overmodulation, i.e., $m>2 / \sqrt{3}$, the peak of the modulating signal exceeds that of the carrier, as illustrated for $m=4 / 3$ in figure 15 .

Depending on the value of $\mathrm{m}$, the overmodulation region gets divided into two non-linear ranges with this PWM method as brought out below. The average voltage vector is studied in each of these ranges.

3.3a Ranges of $m$ : With common-mode injection PWM, the modulating signal has two peaks in each half cycle as seen from figure $3 b$ and figure 15 . When $m$ is slightly greater than $2 / \sqrt{3}$, each phase gets clamped over two intervals (around these peaks) in each half cycle for a total duration of $\theta_{\text {clamp }}$.

The case of $0^{\circ}<\theta_{\text {clamp }}<120^{\circ}$ is illustrated by the three-phase average pole voltages for $m=1.244$ in figure 16a. As seen from figure 16a, whenever one phase is clamped to the positive dc bus, another phase is clamped to the negative dc bus. Thus, two of the phases are clamped in certain carrier cycles, while no phase is clamped in the other carrier cycles. 


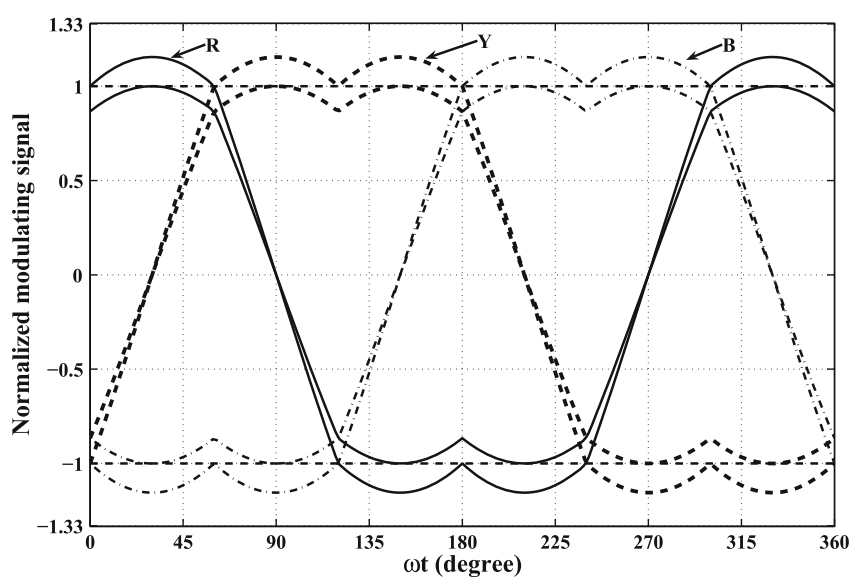

Figure 15. Three phase normalized sinusoidal modulating signals of common-mode voltage injection PWM with $V_{m} / V_{p}=1.1547$ and 1.33 .

Two phases are clamped in any given carrier cycle, when each phase is clamped for a duration of $120^{\circ}$ in each half cycle, i.e., $\theta_{\text {clamp }}=120^{\circ}$. This corresponds to $m=4 / 3$, which is illustrated in figure 15.

For any $m>4 / 3$, the average pole voltage of any phase closely resembles a trapezoidal wave whose flat portion is longer than $120^{\circ}$ in each half cycle. This is illustrated for $m=2$ in figure 16b. Under such condition, i.e., when $120^{\circ}<\theta_{\text {clamp }}<180^{\circ}$, all three phases are clamped in certain carrier cycles, while only two phases are clamped in the rest. When $\theta_{\text {clamp }}=180^{\circ}$, six-step operation is achieved.

Thus, with common-mode injection PWM, the overmodulation region gets divided into two non-linear ranges, namely $0^{\circ}<\theta_{\text {clamp }}<120^{\circ}$ and $120^{\circ}<\theta_{\text {clamp }}<180^{\circ}$. The corresponding ranges of $m$ are $2 / \sqrt{3}<m<4 / 3$ and $4 / 3<m<\infty$, respectively, as indicated in table 2 .

The average voltage vector is analysed in the linear range and the two non-linear ranges. The results of the analysis for $m=1.1547,1.244,2$ and $\infty$ are presented in figure 17 to figure 19.

3.3b Linear range $m \leq \frac{2}{\sqrt{3}}$ : For $m=1.1547$, the two-phase average voltages are sinusoidal as seen from figure 17a. Correspondingly, the magnitude of the average voltage vector is constant

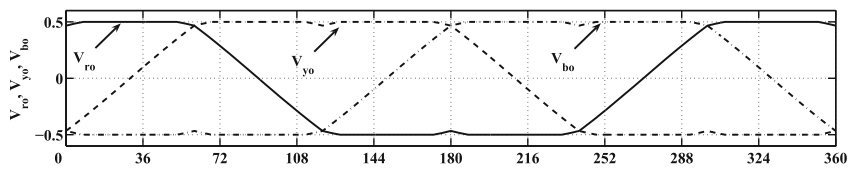

(a)

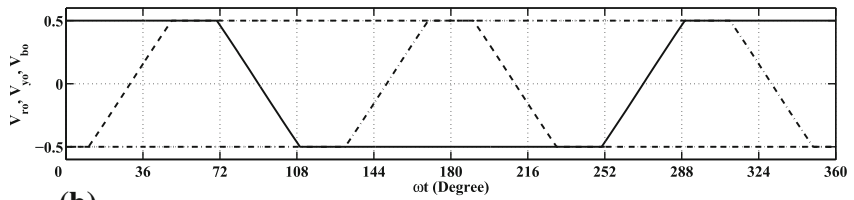

(b)

Figure 16. Three-phase average pole voltages $V_{r o}, V_{y o}, V_{b o}$, normalized with respect to $V_{d c}$, at $(\mathbf{a}) \mathrm{m}=$ 1.244 , and (b) $\mathrm{m}=2$ with common-mode injection PWM. 
Table 2. Ranges of $\theta_{\text {clamp }}, \mathrm{m}$ and MI for CSVPWM.

\begin{tabular}{lcc}
\hline Range of $\theta_{\text {clamp }}$ & Range of $\mathrm{m}$ & Range of MI \\
\hline- & $(0,2 / \sqrt{3})$ & $(0,0.907)$ \\
$\left(0^{\circ}, 120^{\circ}\right)$ & $(2 / \sqrt{3}, 4 / 3)$ & $(0.907,0.952)$ \\
$\left(120^{\circ}, 180^{\circ}\right)$ & $(4 / 3, \infty)$ & $(0.952,1)$ \\
\hline
\end{tabular}

as shown by figure 18a and figure 19a. The angle of the average vector varies linearly with time as seen from figure 18a. In other words, the angular velocity of the average voltage vector is constant. Thus, the average voltage vector has a constant magnitude and uniform angular velocity, as should be expected, during linear modulation.

3.3c Non-linear range- $A\left(\frac{2}{\sqrt{3}}<m \leq 4 / 3\right)$ : In this range, the two-phase average voltages are non-sinusoidal as illustrated for $m=1.244$ in figure $17 \mathrm{~b}$. This translates into variation in the magnitude of the average voltage vector as seen from figure $18 \mathrm{~b}$ and figure $19 \mathrm{~b}$. The angle of the average voltage vector still varies almost linearly with time, and hence, the angular velocity is almost constant in this range of modulation.

3.3d Non-linear range- $B\left(\frac{4}{3}<m<\infty\right)$ : The two-phase average voltages are much more distorted in the non-linear range $\mathrm{B}$ than in the non-linear range $\mathrm{A}$ as can be seen from figure $17 \mathrm{c}$ and figure $17 \mathrm{~b}$. Each average phase voltage remains constant over certain intervals as seen from figure $17 \mathrm{c}$. During the overlapping intervals when both the average phase voltages are constant, the average voltage vector applied is unchanged. The magnitude of the average vector is $V_{d c}$ and the angle of the average vector is unchanged during such intervals as brought out by figure $18 \mathrm{c}$. An active vector is applied continually during such intervals just as in case of overmodulation zone-II with the standard two-zone algorithm. One can see that the variation of the angle of the average vector with time in figure $18 \mathrm{c}$ is quite similar to that in figure 8 . Thus, the modulating signal in figure $3 \mathrm{~b}$ is not only equivalent to CSVPWM during linear modulation, these are equivalent during overmodulation also.
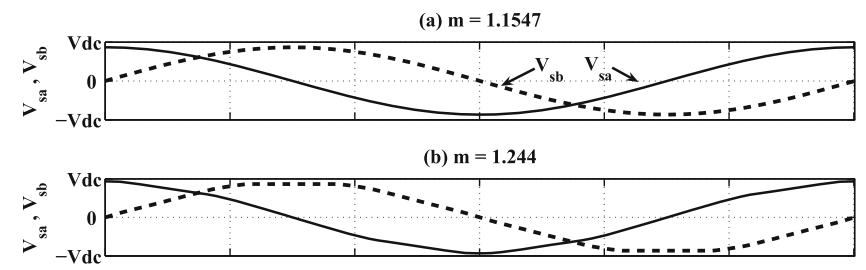

(c) $\mathbf{m}=\mathbf{2}$
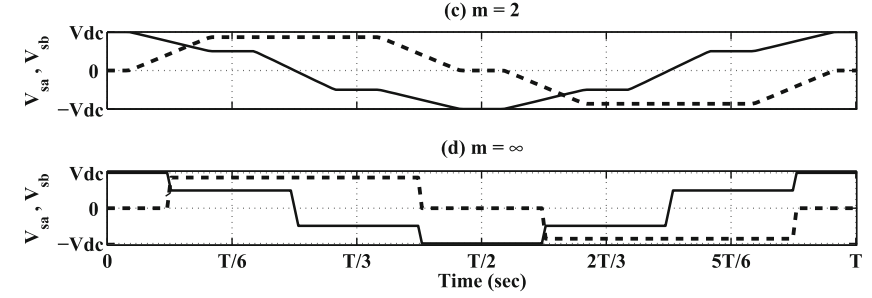

Figure 17. Two-phase average voltage $\left(V_{s a}, V_{s b}\right)$ of common-mode voltage injection PWM for $m=$ $1.1547,1.244,2$ and $\infty$. 

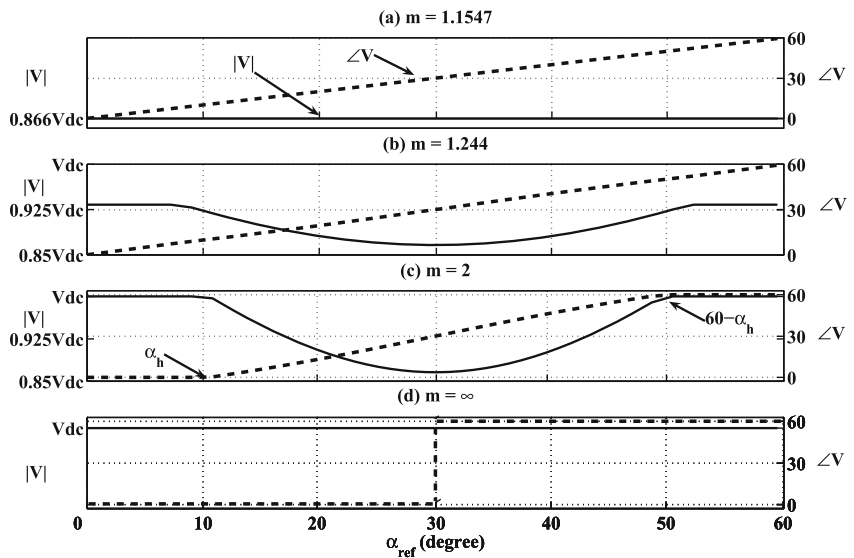

Figure 18. Magnitude $(|V|)$ and position of the average voltage vector with common-mode voltage injection PWM for $m=1.1547,1.244,2$ and $\infty$.

\subsection{Modulation index}

The modulation index $(M I)$ is the peak phase fundamental voltage applied, normalized with respect to $2 V_{d c} / \pi$, as mentioned in section 2 . A plot of the peak-phase fundamental voltage against ' $\mathrm{m}$ ' for the common-mode voltage injection PWM is shown in figure 20. The corresponding plot for SPWM is also shown in the same figure. A nominal switching frequency of $5 \mathrm{kHz}$ is assumed for the plots.

With SPWM, the relationship of $m$ and $M I$ is linear up to $m \leq 1$, and non-linear for $m>1$. With common-mode injection PWM, the relationship is linear up to $m=2 / \sqrt{3}$, and non-linear for $m>2 / \sqrt{3}$ as seen from figure 20. The ranges of $m$ and the corresponding ranges of $M I$ for SPWM and common mode injection PWM are given in tables 1 and 2, respectively.

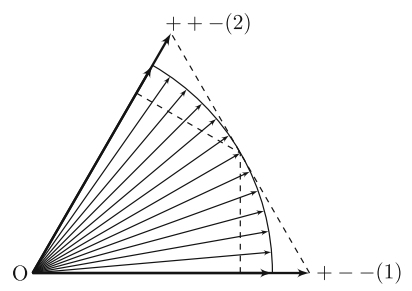

(a) $m=\frac{2}{\sqrt{3}}$

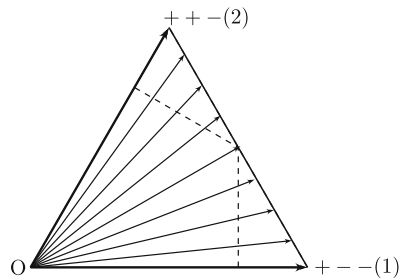

(c) $m=2$

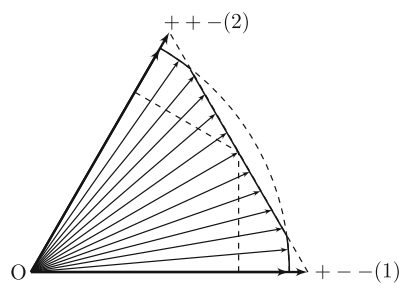

(b) $m=1.244$

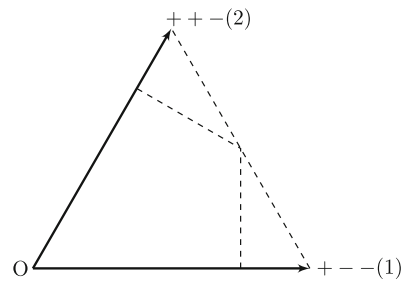

(d) $m=\infty$

Figure 19. Average voltage vectors produced with common-mode voltage injection PWM for $m=$ $1.1547,1.244,2$ and $\infty$. 


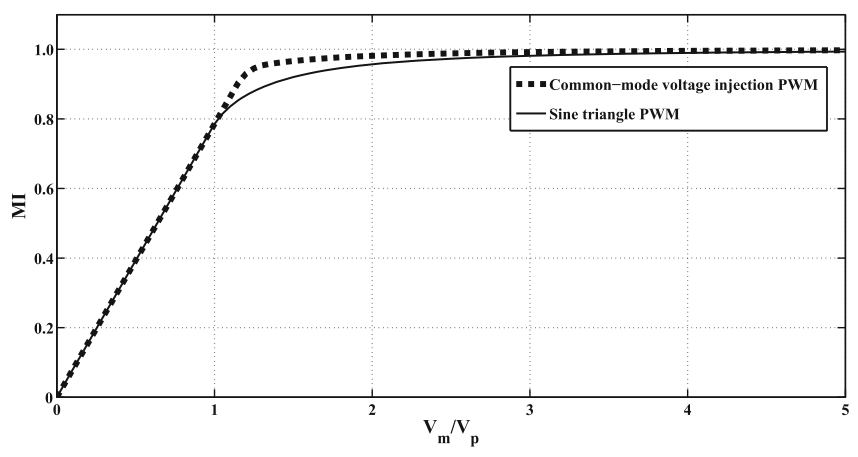

Figure 20. Variation of modulation index (MI) versus $m$.

\section{Two zone overmodulation algorithm for space vector-based PWM}

In space vector-based PWM, the reference vector provided might not be realizable quite often during overmodulation. The actual voltage vector applied $(\mathbf{V})$ is different from the reference vector provided $\left(\mathbf{V}_{\text {ref }}\right)$. The procedure for calculating the magnitude and angle of $\mathbf{V}$ is usually given by the overmodulation algorithm employed (Holtz et al 1993; Lee \& Lee 1998; Narayanan \& Ranganathan 2001, 2002; Venugopal \& Narayanan 2006; Bolognani \& Zigliotto 1997). With the standard two-zone algorithm, the expressions for the magnitude $\mathbf{V}$ and angle $\alpha$ are as given by (6) and (7) for zone-I and zone-II, respectively. While the standard two-zone algorithm is widely used, the basis for these expressions in (6) and (7) is not well-understood as mentioned earlier. However, these expressions can be derived based on the analysis in section 2.2 and section 3.3 as discussed below.

The expressions used in the two-zone algorithm can be derived based on the variation of average voltage vector presented in figures 12 to 19 (particularly figure 13 and figure 18). As seen from figure $18 \mathrm{~b}(m=2, M I=0.94)$, the angle of the applied voltage vector $(\alpha)$ varies linearly with fundamental angle. In fact, it is equal to the angle of reference vector $\alpha_{r e f}$ as indicated in (13).

$$
\alpha=\angle V=\alpha_{r e f}
$$

The variation of the magnitude $|V|$ in figure $18 \mathrm{~b}$ can be expressed as shown in (14). This gives the magnitude $|V|$ of the applied average voltage vector.

$$
|V|=\left\{\begin{array}{lc}
V_{c i r}, & 0 \leq \alpha_{\text {ref }} \leq \alpha_{\text {cir }} \\
\frac{\sqrt{3} / 2}{\cos \left(\frac{\pi}{6}-\alpha_{r e f}\right)}, & \alpha_{c i r}<\alpha_{\text {ref }} \leq\left(\frac{\pi}{3}-\alpha_{c i r}\right) \\
V_{c i r}, & \left(\frac{\pi}{3}-\alpha_{c i r}\right)<\alpha_{\text {ref }} \leq\left(\frac{\pi}{3}\right) .
\end{array}\right.
$$

Now, referring to figure $13 \mathrm{~d}$ and figure 18c, the expression for $\alpha$ in overmodulation zone-II can be obtained. Initially, $\alpha$ is zero up to certain angle. Let us designate this angle as $\alpha_{h}$. Similarly 
$\alpha=60^{\circ}$ for $\alpha_{\text {ref }}$ varying between $\left(60^{\circ}-\alpha_{h}\right)$ and $60^{\circ}$. The variation is almost linear in the intermediate region. The angle $\alpha$ can be expressed in terms of $\alpha_{r e f}$ and $\alpha_{h}$ as given in (15).

$$
\alpha=\left\{\begin{array}{lc}
0, & 0 \leq \alpha_{\text {ref }} \leq \alpha_{h} \\
\frac{\pi}{6}\left(\frac{\alpha_{r e f}-\alpha_{h}}{\frac{\pi}{6}-\alpha_{h}}\right), & \alpha_{h}<\alpha_{r e f} \leq\left(\frac{\pi}{3}-\alpha_{h}\right) \\
\left(\frac{\pi}{3}\right), & \left(\frac{\pi}{3}-\alpha_{h}\right)<\alpha_{r e f} \leq\left(\frac{\pi}{3}\right) .
\end{array}\right.
$$

The corresponding expression for $V$ is given by (16)

$$
|V|=\frac{\sqrt{3} / 2}{\cos \left(\frac{\pi}{6}-\alpha\right)} .
$$

Thus, the expressions for $V$ and $\alpha$ in zone-II of the standard two-zone algorithm can be derived based on the study of the average voltage vector in non-linear range C with SPWM and nonlinear range B in common-mode injection PWM.

\section{Analysis in synchronously revolving reference frame}

The average voltage vector can be transformed from the stationary (a-b) frame to synchronously revolving (d-q) referenceframe. The average voltages along a-axis and b-axis, (i.e., $V_{s a}$ and $V_{s b}$ ), can be transformed into average voltages along $\mathrm{d}$-axis and q-axis as shown in (17).

$$
\left(\begin{array}{l}
V_{d s} \\
V_{q s}
\end{array}\right)=\left(\begin{array}{cc}
\sin (\omega t) & -\cos (\omega t) \\
\cos (\omega t) & \sin (\omega t)
\end{array}\right)\left(\begin{array}{c}
V_{s a} \\
V_{s b}
\end{array}\right) .
$$

$V_{\text {ref }}$ revolves with synchronous frequency ' $\omega$ '. This appears as a constant in the synchronously revolving reference frame. In such a frame of reference, only the error voltage vector varies with time at steady state.

With SPWM the variations in $V_{q s}$ and $V_{d s}$ with the fundamental angle over a sector for different values of $m$ are shown in figure 21. During linear modulation or $m \leq 1$, there is no error between the reference vector and applied voltage vector. Hence $V_{q s}$ is constant and $V_{d s}$ is zero as shown in figure 21. For $(1<m \leq 2), V_{d s}$ is almost zero throughout the sector; however $V_{q s}$ varies with fundamental angle as shown for $m=1.35$ and $m=2$ in figure 21 .

In case of common-mode voltage injection PWM, the variations in $V_{d s}$ and $V_{q s}$ with $\alpha_{r e f}$ for different values of $m$ are as shown in figure 22. During linear modulation or $m \leq 2 / \sqrt{3}$, there is no error between the reference vector and applied voltage vector. Hence $V_{q s}$ is constant, and $V_{d s}$ is zero, as shown in figure 22. For $(2 / \sqrt{3})<m \leq(4 / 3), V_{d s}$ is almost zero throughout the sector; however, $V_{q s}$ varies with fundamental angle as shown for $m=1.24$ and $m=1.33$ in figure 22. For $m>(4 / 3)$, both $V_{q s}$ and $V_{d s}$ vary with fundamental angle as seen.

The average value of $V_{q s}$ over a sector $\left(V_{q s(A V)}\right)$, defined in (18), is a measure of the fundamental voltage.

$$
V_{q s(A V)}=\frac{3}{\pi}\left[\int_{0}^{\frac{\pi}{3}}\left(V_{q s}\right) d \alpha_{r e f}\right] .
$$



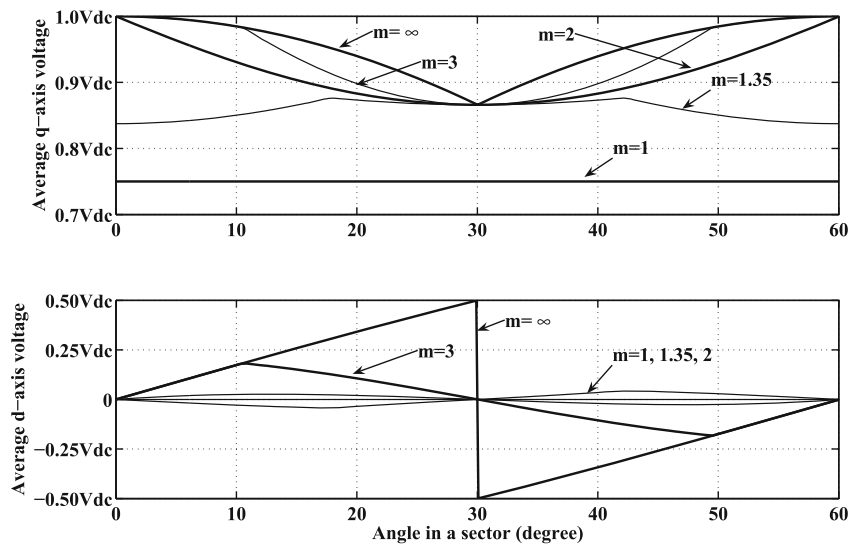

Figure 21. Average $\mathrm{q}$ and d-axis voltages of the average voltage vector (V) for SPWM.

The average value of $V_{d s}$ over a sector $V_{d s(A V)}$ is always zero as shown below:

$$
V_{d s(A V)}=\frac{3}{\pi}\left[\int_{0}^{\frac{\pi}{3}}\left(V_{d s}\right) d \alpha_{r e f}\right]=0 .
$$

The average error voltages along $\mathrm{d}$-axis and $\mathrm{q}$-axis are:

$$
\begin{aligned}
& \tilde{V}_{q s}=V_{q s}-V_{q s(A V)} \\
& \widetilde{V}_{d s}=V_{d s} .
\end{aligned}
$$

The RMS value of the error voltage along q-axis and d-axis can be determined as follows:

$$
\widetilde{V}_{q s, R M S}=\sqrt{\frac{3}{\pi}\left[\int_{0}^{\frac{\pi}{3}}\left(V_{q s}\right)^{2} d \alpha_{r e f}\right]}
$$
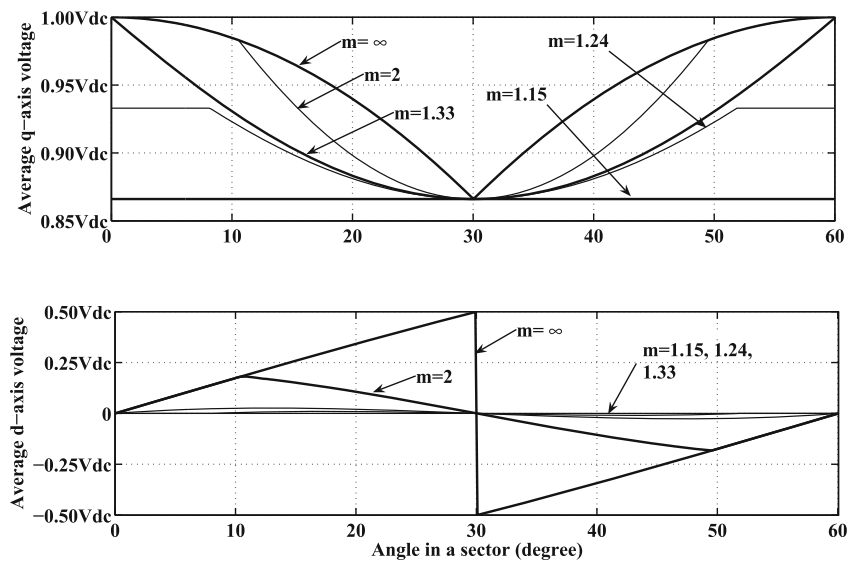

Figure 22. Average $\mathrm{q}$ and d-axis voltages of the average voltage vector (V) for common-mode voltage injection PWM. 


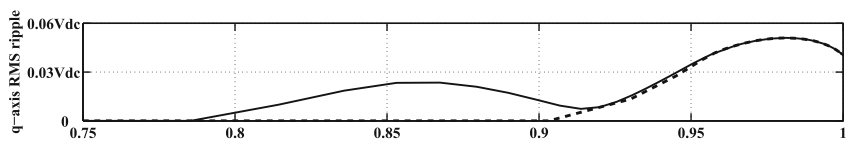

(a)

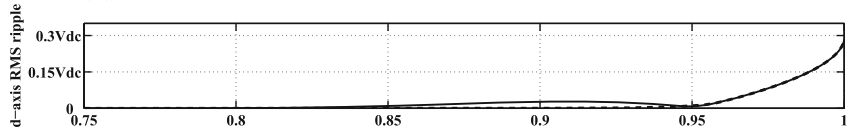

(b)

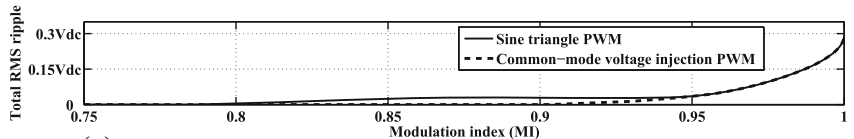

(c)

Figure 23. Average q-axis, d-axis and total RMS voltage ripple of the voltage vector.

$$
\widetilde{V}_{d s, R M S}=\sqrt{\frac{3}{\pi}\left[\int_{0}^{\frac{\pi}{3}}\left(V_{d s}\right)^{2} d \alpha_{r e f}\right]} .
$$

The total RMS voltage ripple is defined as

$$
\widetilde{V}_{R M S}=\sqrt{\widetilde{V}_{q s, R M S}^{2}+\widetilde{V}_{d s, R M S}^{2}}
$$

This gives the RMS value of the sum of the low-order harmonic voltages in the inverter output. This quantity can be used as a basis for comparison of the low-frequency distortion due to different PWM techniques during overmodulation. Figure 23 shows the q-axis, d-axis and the total RMS voltage ripple for the two techniques, namely SPWM and common-mode injection PWM.

In common-mode injection PWM, $\widetilde{V}_{q s}$ is zero up to the $M I=0.907$, and $\widetilde{V}_{d s}$ is almost negligble up to $M I=0.952$. Hence common-mode injection PWM results in lower harmonic distortion than SPWM in the range of $M I$ between 0.785 and 0.952 . However, in the higher range of $M I$, the RMS q-axis and d-axis ripple for both techniques are comparable.

\section{Experimental results}

SPWM and common-mode voltage injection PWM are implemented on a laboratory prototype. The prototype is a $2.3 \mathrm{~kW}, 420 \mathrm{~V}, 50 \mathrm{~Hz}, \Delta$-connected, three phase induction motor drive fed from an IGBT-based $10 \mathrm{kVA}$ inverter. A constant $V / f$ drive is run with a PWM modulator operating in overmodulation region. The DC bus voltage is $540 \mathrm{~V}$, which yields the rated voltage under six-step mode. The switching frequency (before pulse dropping) is $5 \mathrm{kHz}$. The controller platform used is TMS320LF2407A DSP processor (Texas Instruments 2011). Figure 24 shows the measured no-load current waveforms pertaining to SPWM at different fundamental frequencies. Figure 25 shows similar results pertaining to common-mode injection PWM.

The motor drive enters into overmodulation at a fundamental frequency of magnitude $39.25 \mathrm{~Hz}$ with SPWM. Considerable distortion is seen in the no-load current waveform at $f=44 \mathrm{~Hz}$. With common mode injection, there is no such distortion at $44 \mathrm{~Hz}$ since the modulation is linear up to $45 \mathrm{~Hz}$. With further increase in fundamental frequency, the harmonic distortion increases in both cases. 


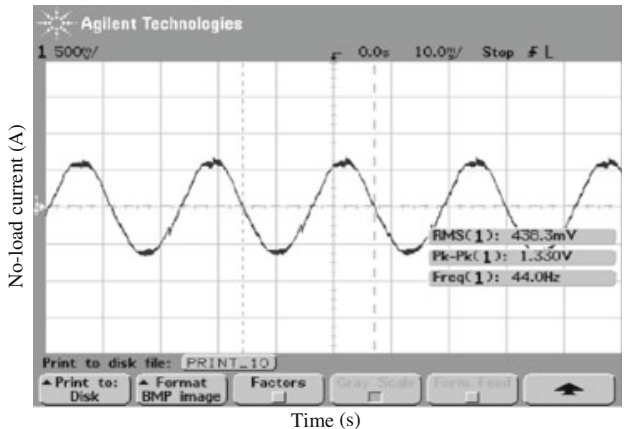

(a) No-load current at $44 \mathrm{~Hz}, m=1.25$ and $M I=0.88$

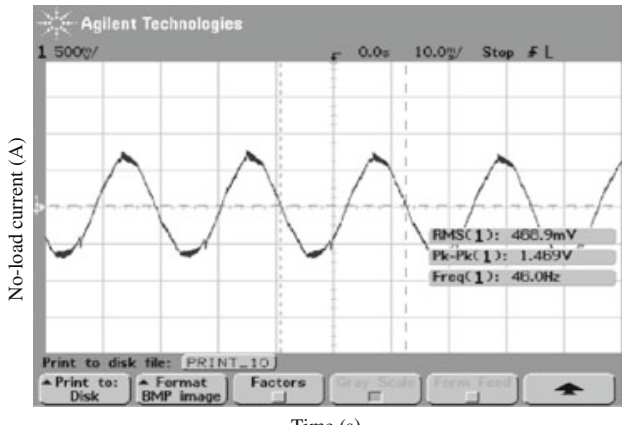

(b) No-load current at $46 \mathrm{~Hz}, m=1.49$ and $M I=0.92$

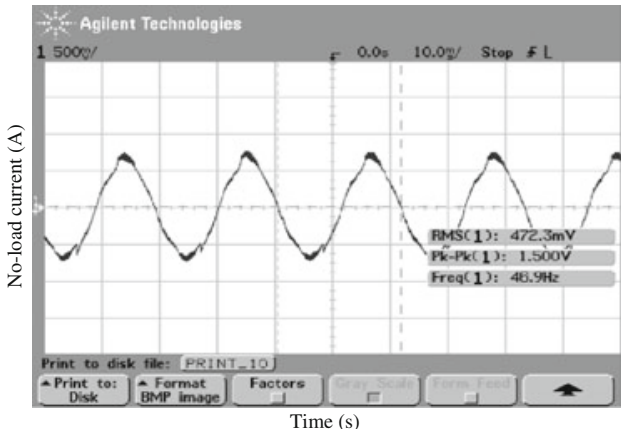

(c) No-load current at $48 \mathrm{~Hz}, m=2.08$ and $M I=0.96$

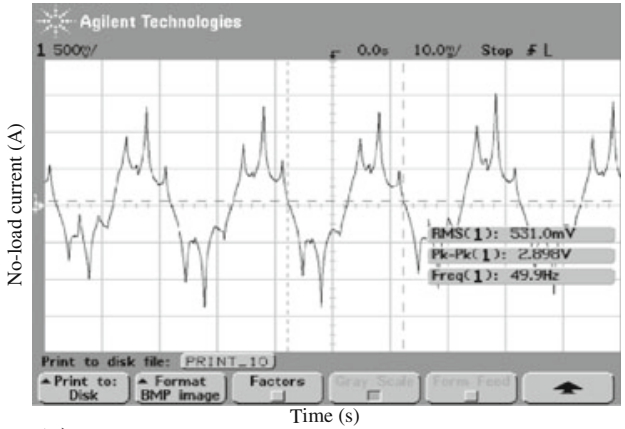

(d) No-load current at $50 \mathrm{~Hz}$ and $M I=1.0$ (six step mode)

Figure 24. Experimental results with sine-triangle PWM, scale $=y$-axis: $1.6 \mathrm{~A} / \mathrm{div}$ and $\mathrm{x}$-axis: $10 \mathrm{~ms} / \mathrm{div}$. The measured values of peak currents are (a) 2.13A, (b) $2.35 \mathrm{~A}$, (c) $2.4 \mathrm{~A}$ and (d) $4.6 \mathrm{~A}$. 


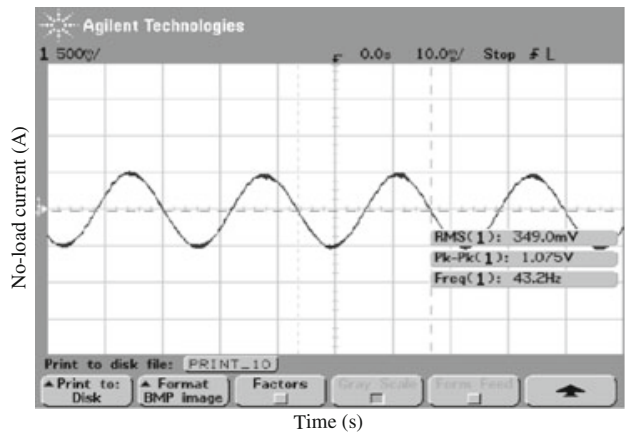

(a) No-load current at $44 \mathrm{~Hz}, m=1.12$ and $M I=0.88$

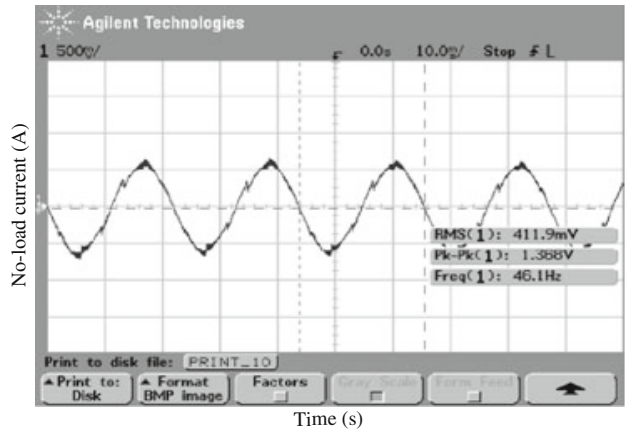

(b) No-load current at $46 \mathrm{~Hz}, m=1.18$ and $M I=0.92$

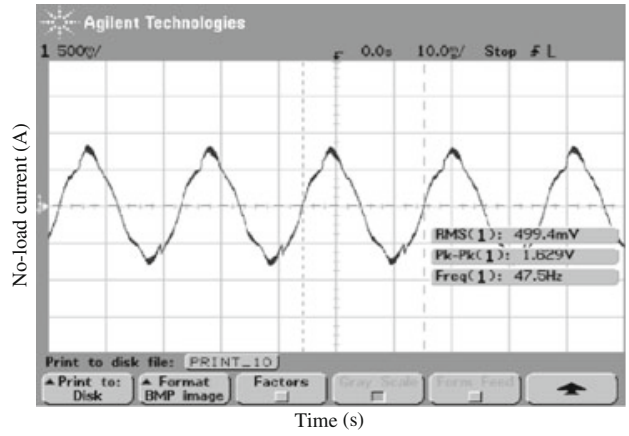

(c) No-load current at $48 \mathrm{~Hz}, m=1.33$ and $M I=0.96$

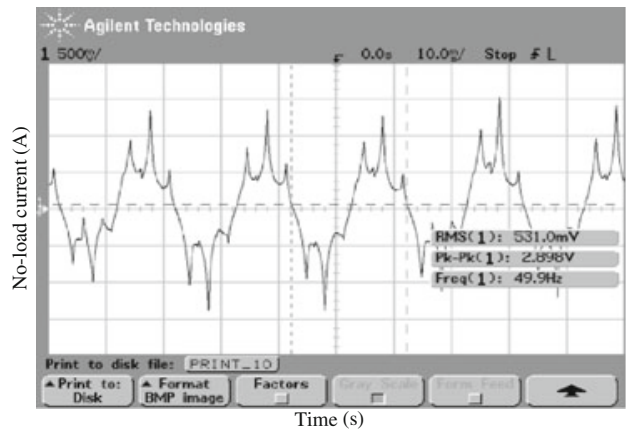

(d) No-load current at $50 \mathrm{~Hz}$ and $M I=1.0$ (six step mode)

Figure 25. Experimental results with common mode voltage injection $\mathrm{PWM}$, scale $=\mathrm{y}$-axis: $1.6 \mathrm{~A} / \mathrm{div}$ and x-axis: $10 \mathrm{~ms} / \mathrm{div}$. The measured values of peak currents are (a) $1.72 \mathrm{~A},(\mathbf{b}) 2.2 \mathrm{~A}$, (c) $2.6 \mathrm{~A}$ and (d) $4.6 \mathrm{~A}$. 


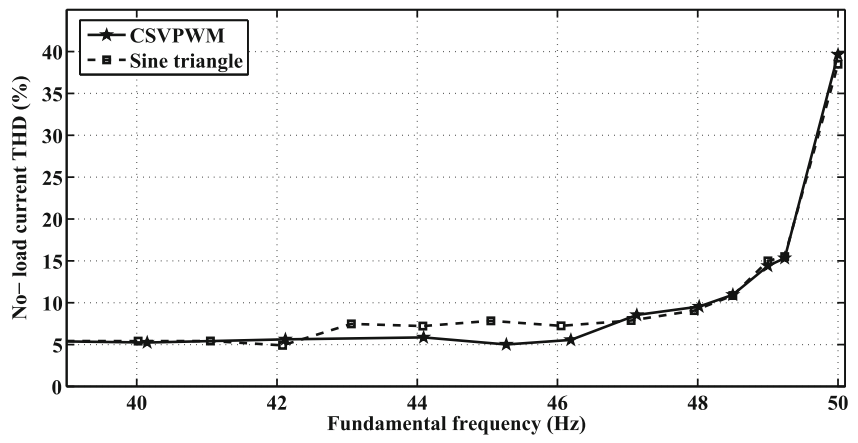

Figure 26. Comparison of measured no-load current THD for sine-triangle PWM and common mode voltage injection PWM.

Table 3. Theoretical low-frequency RMS voltage ripple and measured no-load current THD.

\begin{tabular}{llccccc}
\hline & & \multicolumn{2}{c}{ RMS voltage ripple } & & \multicolumn{2}{c}{ No-load current THD (\%) } \\
Freq. (Hz) & $M I$ & SPWM & CSVPWM & & SPWM & CSVPWM \\
\hline 42 & 0.84 & 0 & 0 & 5 & 5 \\
44 & 0.88 & $0.03 V_{d c}$ & 0 & & 7 & 5 \\
46 & 0.92 & $0.04 V_{d c}$ & $0.01 V_{d c}$ & & 7.8 & 6 \\
48 & 0.96 & $0.045 V_{d c}$ & $0.045 V_{d c}$ & & 10 & 10 \\
50 & 1 & $0.29 V_{d c}$ & $0.29 V_{d c}$ & & 40 & 40 \\
\hline
\end{tabular}

The total harmonic distortion of current can be defined as

$$
I_{T H D}=\frac{\sqrt{I_{R M S}^{2}-I_{1}^{2}}}{I_{1}},
$$

where $I_{R M S}$ is the total RMS current and $I_{1}$ is the fundamental RMS current. The THD is measured for SPWM technique at various fundamental frequencies. Similar measurements for common-mode voltage injection PWM are also done. The relative values of measured current THD shown in figure 26 agree with the relative values of RMS voltage ripple shown in figure 23c. The theoretical and experimental results are also tabulated in table 3.

\section{Discussion}

The entire range of modulation can be divided into four ranges in terms of $M I$ as indicated below. The findings of this work, pertaining to the four ranges, are summarized in this section.

\subsection{Modulation range $0<M I<0.785$}

The relation between $m$ and $M I$ is linear for both SPWM and common-mode injection PWM in this range. Hence this is termed as 'linear modulation range'. There is no low-frequency harmonic distortion in the output voltage in this range. Only switching-frequency harmonics are present in the inverter output. Common-mode injection PWM leads to lower THD than SPWM 
as has been shown earlier (Chung et al 1998; Cataliotti et al 2007; Zhou \& Wang 2002; Varma \& Narayanan 2006).

\subsection{Modulation range $0.785<M I<0.907$}

With SPWM, the relation between $m$ and $M I$ is non-linear, and also there is low-frequency distortion in the inverter ouput voltage in this range of modulation. This distortion is seen as variation in the magnitude of the average voltage vector, whose angular velocity is still constant. This magnitude variation over a cycle (or sector) translates into average q-axis voltage ripple in the synchronously revolving reference frame.

However, with the common-mode injection PWM, $m$ and $M I$ are related linearly. Hence this range can be termed as 'extended linear modulation range'. Also there is no low-frequency distortion in the inverter ouput. The magnitude and angular velocity remain constant as in case of linear modulation. There is no ripple in the average d-axis or q-axis voltages. Hence common-mode injection PWM leads to significantly lower THD than SPWM. One can use common-mode injection PWM for many applications including motor drives except for threephase four-wire systems and applications sensitive to common-mode voltage such as aerospace or marine applications.

\subsection{Modulation range $0.907<M I<0.952$}

In this range, the relation between $m$ and $M I$ is non-linear for both SPWM as well as commonmode injection PWM. Also, the angular velocity of the average vector is constant with both the methods. However, the magnitude of the average voltage vector begins to vary in this range in case of common-mode injection PWM; the variation in magnitude becomes much more pronounced than in the earlier range in case of SPWM. Hence there is considerable ripple in the average q-axis voltage for both methods. While there is low-frequency distortion in the output with both the methods, the distortion is lower with common-mode injection PWM than with SPWM.

The harmonic distortion in this range is much lower than that of six-step mode. Hence, from the point of view of low-frequency distortion, the operation of an inverter or a motor drive could be extended only up to this range rather than up to the six-step mode.

\subsection{Modulation range $0.952<M I<1.0$}

In this range also, the relation between $m$ and $M I$ is non-linear for both the methods. Both the magnitude and angular velocity of the average voltage vector vary over a sector for both the methods. Because of the variations in magnitude as well as angular velocity, both q-axis and daxis voltage ripple are considerable for both methods. The harmonic distortion increases steeply as the operation approaches six-step mode.

\section{Conclusion}

The overmodulation process in sine-triangle PWM (SPWM) is studied from a space vector perspective. The overmodulation region can be divided into three ranges with SPWM. With common mode injection (equivalent to CSVPWM), the overmodulation region gets divided into two ranges. The ranges differ in terms of the number of phases clamped. 
With any triangle comparison PWM, the average voltage in the stationary reference frame has a constant magnitude and constant angular velocity in the linear modulation region. After the onset of overmodulation, the angular velocity continues to remain constant (or almost constant) and the magnitude starts varying. Closer to the six-step mode, the angular velocity also becomes non-uniform. Thus, the overmodulation process in SPWM (or any triangular-comparison PWM) is quite similar to the overmodulation of space vector modulated inverter using standard twozone algorithm. It is shown that the two-zone algorithm itself can be derived based on the above study. While the equivalence of common-mode injection PWM and conventional space vector PWM during linear modulation is well known (Varma \& Narayanan 2006), this work brings out the similarity between the two methods during overmodulation. Thus, this work serves to unify the understanding of overmodulation from the per-phase as well as the space vector points of view.

Further, the analysis in a synchronous revolving (d-q) reference frame yields a method for calculating the RMS value of low-order voltage ripple. This can be used to compare the distortion due to different PWM methods during overmodulation. The relative values of measured current THD during overmodulation tally well with the relative values of analytically calculated RMS voltage ripple.

\section{References}

Asiminoaei L, Rodriguez P and Blaabjerg F 2008 Application of discontinuous PWM modulation in active power filters. IEEE Transactions on Power Electronics 23(4): 1692-1706

Beig A R 2012 Synchronized SVPWM algorithm for the overmodulation region of a low switching frequency medium-voltage three level VSI. IEEE Trans. on Industrial Electronics 59(12): 4545-5454

Binoj Kumar A C, Prasad J S S and Narayanan G 2013 Experimental investigation on the effect of advanced bus-clamping pulse width modulation on motor acoustic noise. IEEE Trans. on Industrial Electronics 60(2): 433-439

Bolognani J and Zigliotto M 1997 Novel digital continuous control of SVM inverter in the overmodulation region. IEEE Transactions on Industrial Application 33: 525-530

Bose B K 2009 Power electronics and motor drives: recent progress and perspective. IEEE Transactions on Industrial Electronics 56(2): 581-588

Cataliotti A, Genduso F, Raciti A and Galluzzo G R 2007 Generalized PWM-VSI control algorithm based on a universal duty cycle expansion: Theoretical analysis, simulation results and experimental validations. IEEE Transactions on Industrial Electronics 54(3): 1569-1580

Chung D-W, Kim J-S and Sul S-K 1998 Unified voltage modulation technique for real-time three phase power conversion. IEEE Transactions on Industrial Application 34(2): 374-380

Holtz J 1992 Pulse width modulation - A survey. IEEE Transactions on Industrial Electronics 39(5): $410-420$

Holtz J 1994 Pulse width modulation for electronic power conversion. Proceedings of IEEE 82(8): $1194-1214$

Holtz J, Lotzkat and Khambadkone A M 1993 On continuous control of PWM inverter in the overmodulation range including thr six step mode. IEEE Transactions on Power Electronics 8: 546-553

Kerkman R J, Rowan T M, Leggate D and Seibel B J 2006 Control of PWM voltage inverter in the pulse dropping region. IEEE Transactions on Power Electronics 10: 559-565

Lee D C and Lee G-M 1998 A novel overmodulation technique for space vector PWM inverters. IEEE Transactions on Power Electronics 13(6): 1144-1151

Mao X, Jain A K and Ayyanar R 2011 Hybrid interleaved space vector PWM for ripple reduction in modular converters. IEEE Transactions on Power Electronics 26(7): 1954-1967 
Modi M K, Venugopal S and Narayanan G 2010 Analysis of overmodulation in sine-triangle PWM from a space vector perspective. National Power Electronics Conference 'NPEC' Rec

Mohan N, Undeland T M and Robbins W P 2003 Power electronics-converters, applications and design, third edition. India: John Wiley

Narayanan G and Ranganathan V T 2000 Triangle-comparison approach and space vector approach to pulsewidth modulation in inverter fed drives. Journal of Indian Institute of Science 80: 409-427

Narayanan G and Ranganathan V T 2001 Overmodulation algorithm for space vector modulated inverters and its application to low switching frequency PWM techniques. IEE Proc. Electric Power Applications 148(6): 521-536

Narayanan G and Ranganathan V T 2002 Extension of operation of space vector PWM strategies with low switching frequency using different overmodulation algorithms. IEEE Transactions on Power Electronics 17(5): 788-798

Prasad J S S, Bhavsar T, Ghosh R and Narayanan G 2008 Vector control of three-phase AC/DC front-end converter. SADHANA Academy Proceedings in Engineering Sciences 33(5): 591-613

Ranganathan V T 1997 Space vector modulation-a status review. SADHANA Academy Proceedings in Engineering Sciences 22(6): 675-688

Ranganathan V T 2010 High power AC motor drives: status review and work at IISc. Journal of Indian Institute of Science 90(3): 327-346

Singh B, Chandra A, Al-Haddad K, Anuradha and Kothari D P 1998 Reactive power compensation and load balancing in electric power distribution system. International Journal of Electrical Power and Energy System 20(6): 375-381

Singh B, Saha R, Chandra A and Al-Haddad K 2009 Static synchronous compensators (STATCOM): a review. IET Power Electronics 2(4): 297-324

Texas Instruments 2011 http://www.ti.com/product/tms320lf2407a. Accessed on Sep. 3, 2011

Varma P S and Narayanan G 2006 Space vector PWM as a modified form of sine-triangle PWM for simple analog or digital implementation. IETE Journal of Research 52(6): 435-449

Venugopal S and Narayanan G 2006 An overmodulation scheme for vector controlled induction motor drives, IEEE-PEDES conference Rec

Vguyen N V, Nguyen B X and Lee H H 2011 An optimized discontinuous PWM method to minimize switching loss for multilevel inverters. IEEE Transactions on Industrial Electronics 58(9): 3958-3966

Wu Y, Shafi M A, Knight A M and McMohan R A 2011 Comparison of the effects of continuous and discontinuous PWM schemes on power losses of voltage-sourced inverters for induction motor drives. IEEE Transactions on Power Electronics 26(1): 182-191

Zhang W, Hou Y, Liu X and Zhou Y 2012 Switched control of three-phase voltage source PWM rectifier under a wide range rapidly varying active load. IEEE Transactions on Power Electronics 27(2): 881-890

Zhao D 2006 Space vector methods for AC drives to achieve high efficiency and superior waveform quality. Ph.D. dissertation. Phoenix: Arizona State Univ. AZ

Zhao D, Hari V S S P K, Narayanan G and Ayyanar R 2010 Space vector based hybrid PWM techniques for reduced harmonic distortion and switching loss. IEEE Transactions on Power Electronics 25(3): 760-774

Zhou K and Wang D 2002 Relationship between Space-vector modulation and three-phase carrier-based PWM: a comprehensive analysis. IEEE Trans. on Industrial Electronics 49(1): 186-196 